Invited Paper

\title{
Advances of Laser Welding Technology of Glass -Science and Technology-
}

\author{
Isamu Miyamoto ${ }^{1,2}$, Kristian Cvecek $^{2,3}$, Michael Schmidt ${ }^{2,3,4}$ \\ ${ }^{1}$ Osaka University, Department of Manufacturing science, 2-1, Yamada-Oka, Suita, Osaka, \\ 565-0871 Japan, \\ E-mail: miyamoto-i@ares.eonet.ne.jp \\ ${ }^{2}$ Erlangen Graduate School of Advanced Optical Technologies, Paul-Gordan Str. 6, \\ 91052 Erlangen, Germany \\ ${ }^{3}$ Friedrich-Alexander-Universiät Erlangen Nürenberg, Paul-Gordan Str. 6, \\ 91052 Erlangen, Germany \\ ${ }^{4}$ Bayerisches Laserzentum, Konrad-Zuse Str. 2-6, 91052 Erlangen, Germany
}

\begin{abstract}
Advances of laser welding technology of glass by continuous wave (CW), ns pulse, and ultrashort pulse (USP) lasers are overviewed in the past two decades from scientific and technological points of view. A novel thermal stress model shows that crack prevention in laser welding of glass depends on whether or not the molten pool has a free-surface. In glass/glass welding by CW laser, crack-freewelding is limited to glass having small coefficient of thermal expansion (CTE) due to the shrinkage stress, since the molten pool has a free-surface. In glass/glass welding by USP laser, crack-free-welding is available independently of glass's CTE if the gap between glass substrates is small, since nonlinear absorption process produces a molten pool having no free-surface so that the shrinkage stress is suppressed. Technical efforts to increase the bridgable gap without cracks using USP laser are demonstrated. In dissimilar welding of glass/metal (or glass/Si), successful weld joint can be obtained using ns and USP lasers by suppressing the melt splash of metal (or Si).
\end{abstract}

DOI: $10.2961 /$ jlmn.2020.02.1001

Keywords: laser welding, glass, thermal stress, crack, molten pool, free-surface, optical contact, dissimilar material welding, mechanical strength

\section{Introduction}

Glass is widely used for different applications in medical, optical and electronics industries due to its excellent physical and chemical properties. In fabrication process of glass components, joining is often involved, and there exist a range of joining processes of glass, including adhesive bonding [1], anodic bonding [2], glass frit joining [3], optical contact [4], eutectic bonding [5], diffusion bonding [6] and welding $[7,8]$. However, most of these procedures cannot provide the required joint performances due to the intrinsic limitation of the additive materials [1,3], the process throughput [6], poor shock resistance [4], necessity for high temperature heating $[2,5,6]$, limited spatial resolution $[2,6]$ and so on. The most promising joining procedure is welding, since it provides monolithic joint structure with high throughput and high spatial resolution. However, despite the superiority of welding among existing joining processes in principle, glass is characterized to one of the most difficult materials for welding due to its brittle property, causing cracks by the thermal stress [11-13]. Thus crack-free laser welding of glass was limited to glass having small CTE like fused silica, while $\mathrm{CW}$ laser welding of glass was reported many years ago $[9,10]$.

In parallel to the rapid progress in USP laser technology at the beginning of the $21^{\text {st }}$ century [14], a variety of revolutionized materials processing technologies have been developed based on nonlinear ionization process using USP lasers $[15,16]$. In glass welding, USP lasers have also changed glass from one of the most difficult-to-weld material to very suitable material by developing breakthrough welding procedure, which allows not only crack-free welding but drastic downsizing for fused silica [17] and shortly borosilicate glass $[18,19]$. However, the underlaying mechanisms for crack-free welding of brittle material by USP laser was unknown at that time, remaining a mystery for a while. The mystery was solved by a thermal stress model [20,21], showing that the shrinkage stress, which is responsible for the cracks in laser welding of glass, is suppressed, if the molten pool with no free-surface is produced in welding process by nonlinear absorption process.

Recently, laser welding technology of glass has progressed rapidly, providing excellent joint performance with versatility, as is reviewed in a lot of publications $[7,15,16$, 21-26]. However, the laser-matter interaction in laser welding of glass has not been fully understood yet, since the welding processes using USP lasers are complexly affected by the laser-glass interaction, which includes linear [7] and nonlinear ionization processes [27-29], plasma shielding [30-32] and heat, material and radiation transfers from the melt glass $[33,34]$. It is expected that better understanding of the laser welding process will, without any doubt, facilitate the further progress of the future laser welding technology of glass.

In the present paper we overview the advances of laser welding technology of glass in the past two decades from scientific and technological points of view. The paper is organized as follows. Section 2 classifies welding modes of glass depending on the laser intensity, and Sections 3 
describes the glass/glass welding by $\mathrm{CW}$ laser. Section 4 details the laser-matter interaction in the glass/glass welding by USP laser, which includes non-linear absorptivity, laserabsorption dynamics, the thermal stress model in glass welding and gap bridging in non-optically contacted samples. Some recent applications of glass/glass welding by USP laser are also demonstrated. Section 5 describes welding of dissimilar materials. Section 6 gives summary and outlook.

\section{Glass welding modes}

Glass can be welded by CW laser and USP laser to which the glass is opaque and transparent, respectively (Fig. 1). In $\mathrm{CW}$ laser welding of glass, the laser energy to which the glass is opaque is absorbed at the glass surface by linear process to provide the molten pool having a free-surface (Fig. 1a,b) similarly to metal welding [7]. The weld bead produced by $\mathrm{CW}$ laser is rather macroscopic, since the extended temperature field is developed under the energy balance between $\mathrm{CW}$ laser and heat diffusion. Crack-free welding is limited to glass having small CTE due to cracks caused by shrinkage stress based on the thermal stress model (Section 4.3) [20]. On the other hand, it has an advantage that even glass substrates with large gap can be successfully welded together by feeding filler glass unlike the case of USP laser welding (Section 3.1) [8].

CW laser welding is classified into two modes: (a) thermal conduction mode and (b) keyhole mode depending on the surface temperature of the molten pool $\mathrm{T}_{\mathrm{S}}$ [7]. The former (a) is produced when $T_{S}<T_{B}\left(T_{B}=\right.$ boiling temperature of glass) where the interior of the bulk glass is heated by the conduction from the substrate surface, and the latter (b) is produced when $T_{S} \geqq T_{B}$. In this process, the melt pool surface is depressed to generate a "keyhole" by the evaporation recoil pressure [35], which is caused by the thousands timesvolume expansion from the liquid phase to the gas phase. In this welding mode, the interior of the bulk glass is heated directly by the laser beam, enabling welding of thick glass plate in a single-pass.

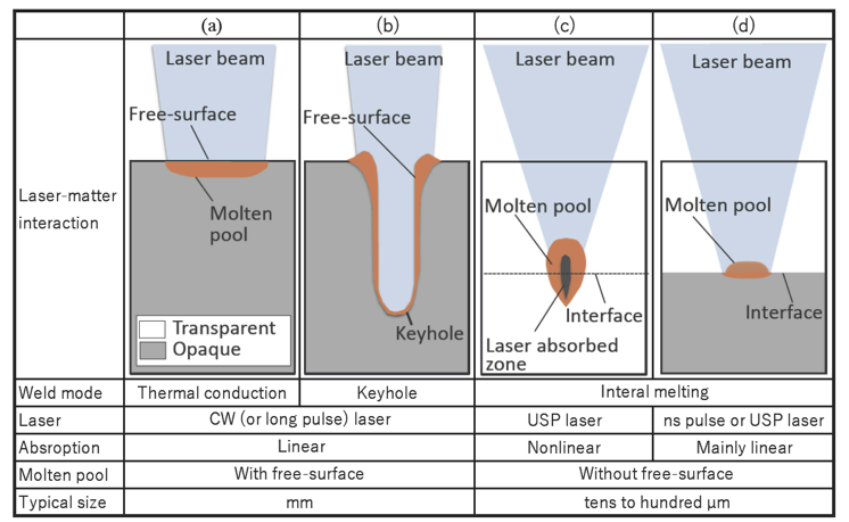

Fig. 1 Laser-matter interaction in laser welding of glass and typical weld bead dimension where molten pool has $(a, b)$ a free-surface and $(\mathrm{c}, \mathrm{d})$ no free-surface in laser welding of glass.

In USP laser welding of glass, the laser energy to which the glass is transparent is absorbed nonlinearly in the limited region near the focus [27-29] where the laser intensity is high enough to trigger nonlinear ionization. Then only the region near the interface is selectively melted without adding absorption material. As the result, a molten pool having no free-surface is produced (Fig. 1c) unlike the case of CW laser welding. In this welding mode, crack-free welding of glass is realized independently of its CTE, because the shrinkage stress is suppressed in USP laser welding as will be detailed in Section 4.3(c) [20]. In this case, however, the gap between the glass substrates has to be kept small enough to avoid the plasma ablation [36] and the free-surface in the molten pool. Besides nonlinear absorption makes the weld bead size much smaller than $\mathrm{CW}$ laser welding, making the microwelding technologies so attractive especially in labon-a-chip or MEMS applications (see Sec. 4.5), for instance, since the laser energy is deposited before the heat diffusion time.

In dissimilar material welding (glass/metal or glass $/ \mathrm{Si}$ ), internal melting mode (molten pool having no free-surface) is also produced at laser intensity below the threshold of multiphoton ionization (MPI) of glass (Fig. 1d). This means that internal melting mode is realized not only by USP laser but by ns pulse laser. In this process, the laser energy is first absorbed at the surface of the opaque material (metal or $\mathrm{Si}$ ) by linear process to heat above $\mathrm{T}_{\mathrm{B}}$, and then the glass is mixed with hot metal (or $\mathrm{Si}$ ) to provide the mixture having the lowered band gap energy. As the result, the laser energy is absorbed also in the glass region by linear process, as will be discussed in Section 5. However, the melt splash can easily occur to deteriorate the weld quality, if the absorption coefficient $\alpha$ of the opaque material increases sensitively as the temperature rises like Si.

\section{Glass/glass welding by $\mathrm{CW}$ laser \\ 3.1 Thermal conduction welding mode}

In $\mathrm{CW}$ laser welding, $\mathrm{CO}_{2}$ laser with a wavelength of $10.6 \mu \mathrm{m}$ is used, which has larger diffraction limited focus spot size. Then rather larger weld bead size (typically $\mathrm{mm}$ ) is produced, since the weld bead is produced by larger defocused laser beam, and the extended temperature field is produced by the heat balance between the absorbed laser energy and the heat diffusion. Besides crack-free welding is limited to glass having small CTE like fused silica, since the molten pool having a free-surface causes the shrinkage stress to generate cracks when cooled down to room temperature, as discussed in Section 4.3(a).

Thick fused silica plates (10 $\mathrm{mm}$ thick) for corner cube was spot-welded using $\mathrm{CW}-\mathrm{CO}_{2}$ laser [37]. Average laser power of $20 \sim 70 \mathrm{~W}$ with $300 \mu \mathrm{m}$ in diameter were irradiated with an optimized time-dependent irradiation programed to obtain spot welding in a thermal conduction mode. In this process, the thickness of the glass plate was reduced to $800 \mu \mathrm{m}$ by supersonic drilling at the incident side, and hence the shallow molten pool of the thermal conduction mode can reach the partner plate. Mechanical strength of $10 \sim 30 \mathrm{~kg}$ was obtained for each weld spot. It is noted that the laser-welded glass pieces are pulled each other by the shrinkage of the molten material in cooling processes to provide visual optical contact, by which the stiffness of the weld joint is greatly increased. This results in an excellent angular stability of the reflected light of $1.87 \mathrm{sec}$ in the laser welded corner cube with a temperature variation of $-60 \sim+40{ }^{\circ} \mathrm{C}$.

Optical fibers were welded to an array of collimator lenses for fiber optical rotary joints (FORJ) by $\mathrm{CW}-\mathrm{CO}_{2}$ laser [38]. The welding technology was developed for the alternative of the existing adhesive bonding, which had 
disadvantages including the limited mechanical strength and the refractive index change with temperature causing the increase in the back reflection of the optical signal. The laser welding system was designed to allow a minimum fiber pitch of $1 \mathrm{~mm}$ using a ring-shaped laser beam by Schwarzschild objective to heat the circumference of the glass fiber uniformly. The cross-section of weld joint shows the optical fiber is uniformly welded to the substrate by the thermal conduction mode with an excellent concave weld seam (Fig. 2). The mechanical strength of the welded optical fiber was as high as $326 \mathrm{MPa}$, which is much higher than the adhesive bonding of $33 \mathrm{MPa}$ [39]. Back reflection of the optical transmission was also reduced by a factor of 10 in comparison with the adhesive bonding.

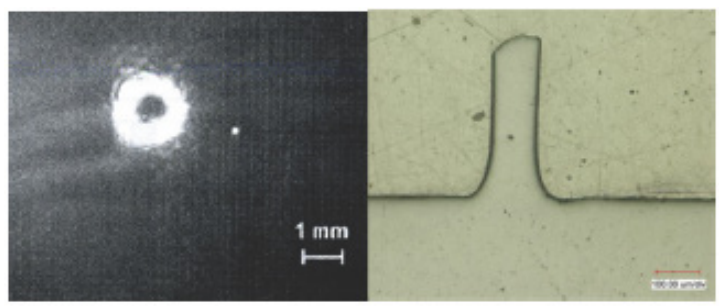

Fig. 2 (a) $\mathrm{CO}_{2}$ laser beam profile for welding the circumference of the glass fiber provided by Schwarzschild objective. (b) Cross-section of optical fiber welded to glass substrate.

Versatility of the CW laser welding is greatly enhanced by feeding glass fiber as the filler material in welding of glass plates having large gap [8]. A corner welding of fused silica plates was developed with a thickness of $2.1 \mathrm{~mm}$ at welding speed of $\mathrm{v}=50 \mathrm{~mm} / \mathrm{min}$ where the surface temperature is monitored for a PID (Proportional-Integral-Differential) feedback control to set the laser power at $200 \mathrm{~Hz}$. In this process the surface temperature was kept below boiling temperature of the glass $\mathrm{T}_{\mathrm{B}}\left(2230^{\circ} \mathrm{C}\right)$ to avoid the deposition of the sublimated powder around the weld zone, so that the post polishing process is removed. The glass fiber with polymer coating of $50 \mu \mathrm{m}$ thickness, which can be evaporated during welding process, was also used for avoiding breaking of glass fiber during feeding with highly reproducible feed rates. The corner gap is successfully filled, providing the excellent surface quality.

\subsection{Keyhole welding mode}

Figure 3(a) shows the keyhole welding in $96 \%$-silicate glass (Vycor 7913, Corning) without cracks after cooling down to room temperature due to small CTE of the glass $(\alpha=$ $\left.7.5 \times 10^{-7} \mathrm{~K}^{-1}\right)[10]$. Note that more than 10 welding passes are needed to weld $15 \mathrm{~mm}$ thick glass plate with the thermal conduction mode [8], and that weld depth can be controlled exactly by changing laser power with monitoring the weld depth from the side.

Figure 3(b) shows the keyhole welding in soda-lime glass by $\mathrm{CW}-\mathrm{CO}_{2}$ laser beam with a focus diameter of 0.3 $\mathrm{mm}$ at different laser powers. Keyhole welding process can be directly observed at much higher spatial and temporal resolutions [10] than the X-ray transmission image in metal welding [40]. It is noted that no cracks are produced during welding enabling direct observation of the keyhole with high spatial and temporal resolution, while cracks are produced in the glass sample after cooled down to room temperature due to the large CTE of the glass. The welding mode changes from thermal conduction mode into a keyhole mode at the laser power higher than $50 \mathrm{~W}$, which corresponds to $\approx 7 \times$ $10^{4} \mathrm{~W} / \mathrm{cm}^{2}$, approximately 2 orders smaller than typical metal welding due to the smaller thermal conductivity of glass [7]. Molten glass flow and spiking [40] in the keyhole which are similar to metal welding [41] were observed. While the welding process observed in glass is different from that of metal due to difference in thermal properties from metal, the direct observation could give some hints for understanding and improving the keyhole welding process.
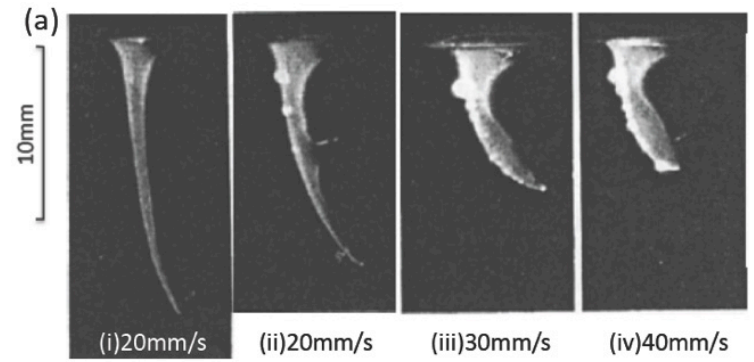

(b)

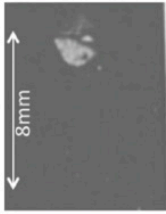

(i) $50 \mathrm{~W}$

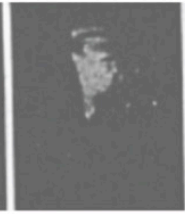

(ii) $70 \mathrm{~W}$

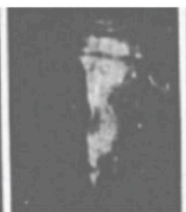

(iii) $100 \mathrm{~W}$

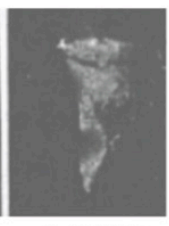

(iv) $120 \mathrm{~W}$
Fig. 3 Direct observation of keyhole in $\mathrm{CW}-\mathrm{CO}_{2}$ laser welding observed in (a) Vycor glass at different welding speeds $\mathrm{v}$ (laser power $\mathrm{W}=90 \mathrm{~W})$, and (b) soda-lime glass at different laser power $\mathrm{W}(\mathrm{v}=$ $70 \mathrm{~mm} / \mathrm{s})$.

\section{Glass/glass welding by USP laser}

First glass welding by USP laser was reported by Tamaki et al. using fs pulse laser in fused silica at a low laser pulse repetition rate of $\mathrm{f}=1 \mathrm{kHz}$, opening the door to the new welding world [17]. The advantages of glass welding by USP laser are downsizing of the weld bead and crack freewelding of glass independently of glass CTE. The former is because the laser energy is absorbed in the pulse duration much shorter than the heat diffusion time, providing significantly smaller weld bead size (typically tens to a hundred $\mu \mathrm{m})$ than CW laser welding. The latter is caused by nonlinear absorption process, which produces the molten pool with no free-surface, as will be described in Section 4.3.

\subsection{Nonlinear absorption in USP laser welding of glass}

Although USP laser welding of glass at a low pulse repetition rate of $\mathrm{f}=1 \mathrm{kHz}$ was also reported in several papers [42-44], the weld joint strength was so low, since the weld bead contains some cracks in the surrounding area due to the tensile stress produced by USP laser impingement [20]. Meanwhile Schaffer et al. [45] reported a heat accumulation effect at higher pulse repetition rates, showing that the melt volume increases with the laser pulse number to make the welding faster and more reliable. It was also proven that cracks produced by the first pulses can be cured by the following laser pulses with multipulse irradiation in heat accumulation regime [20].

Figure 4 shows a typical cross-section of borosilicate glass welding by USP laser in heat accumulation regime, exhibiting a dual structure consisting of the extended inner structure and the elliptical outer structure. The thermal 
conduction model [46] revealed that the laser energy is absorbed in the inner structure (plasma region), where the network modifier is enriched around its contour since the diffusion coefficient of the network modifiers is larger than that of the network formers $[47,48]$. It is noted that the length of the laser absorption region $l$, which is significantly longer than the Raleigh length $z_{R}$ [46], increases with increasing the absorbed laser power $\mathrm{W}_{\mathrm{ab}}$ (Fig. 4c) due to the increased contribution of avalanche ionization [49] as will be detailed in Sec. 4.2. The outer structure is a heat affected zone (HAZ) where the forming temperature (viscosity: $\eta<10^{4} \mathrm{dPas}$ ) is reached [46].
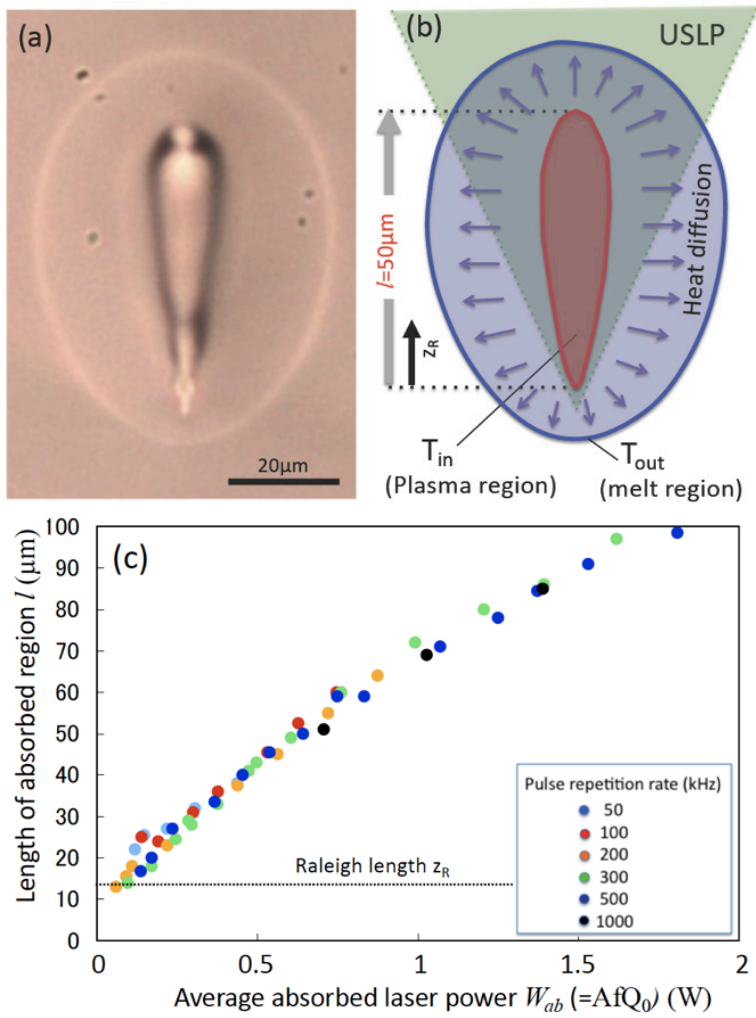

Fig. 4 (a) Cross-section of weld region by USP laser showing dualstructure. (b) Simulated contours of inner and outer structures corresponding to the laser absorption and the melted region, respectively ( $\mathrm{z}_{\mathrm{R}}=$ Rayleigh length). (c) Length of inner structure $l$ plotted vs. absorbed laser power $\mathrm{W}_{\mathrm{ab}}$. As $\mathrm{W}_{\mathrm{ab}}$ increases, $l$ increases where the absorbing plasma moves dynamically $\left(\mathrm{f}=500 \mathrm{kHz}, \tau_{\mathrm{p}}=10 \mathrm{ps}\right.$, $\left.\lambda=1064 \mathrm{~nm}, \mathrm{Q}_{0}=1.59 \mu \mathrm{J}, \mathrm{v}=20 \mathrm{~mm} / \mathrm{s} ; \mathrm{D} 263\right)$.

Nonlinear absorptivity has been evaluated by several authors to determine the effect of pulse energy $Q_{0}[46,50]$, pulse repetition rate $f[46,51,52]$ and the double pulse irradiation $[53,54]$ of USP laser. These results show heat accumulation effect increases not only the melt volume [45] but the non-linear absorptivity and the length of the absorbing region (Fig. 5) [46].

USP laser also enables crack-free welding of dissimilar glass/glass having large difference in thermal properties including CTE, thermal conductivity and melting temperature as shown in Fig. 6 [25]. In this process, laser energy is absorbed in both glasses by nonlinear absorption process to provide the dual-structure, while the discontinuity of the isothermal lines is found at the interface.

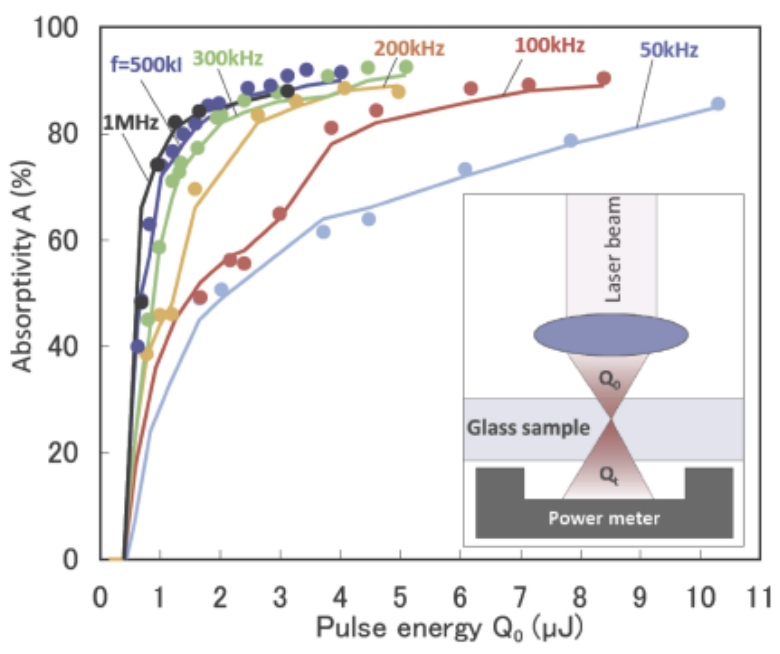

Fig. 5 Nonlinear absorptivity plotted vs. $Q_{0}$ at different values of pulse repetition rate $f$. Solid lines show experimental values $A_{E x}$, and closed circles simulated values $A_{\mathrm{Cal}}\left(\tau_{\mathrm{p}}=10 \mathrm{ps}, \lambda=1064 \mathrm{~nm}, \mathrm{v}\right.$ $=20 \mathrm{~mm} / \mathrm{s}$, NA0.55; D263).

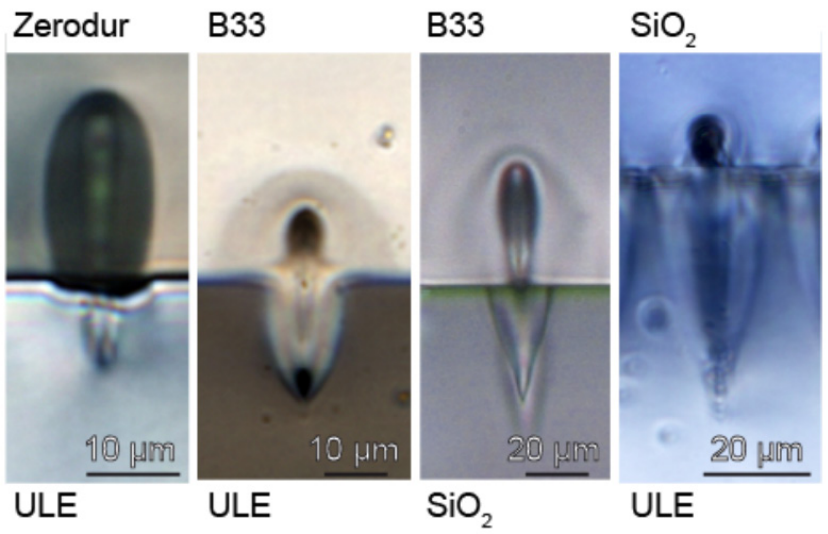

Fig. 6 Examples of dissimilar glass/glass welding by USP laser with OC (with courtesy of Richter et al.)

\subsection{Ionization dynamics in USP laser welding of glass}

Observation of the plasma by a high-speed video camera [49,56-58] shows that a small plasma ball appeared near the focus moves toward the laser source periodically pulse by pulse in USP laser welding of glass in heat accumulation regime (Fig. 7a [49]). The snapshot of the plasma superimposed onto the modified structure (Fig. $7 b, c)$ showed that the plasma moves just within the inner structure in accordance with the thermal conduction model [46].

Numerical simulation of the dynamic plasma behavior at high pulse repetition rate is very complex, because the plasma temperature reaches many thousands ${ }^{\circ} \mathrm{C}$ where thermal ionization plays an important role. This means that the thermal conduction of the plasma in glass has to be taken into consideration in evaluating the evolution of free-electron. The time evolution of free-electron density in conduction band under the influence of the laser light has been simulated based on the rate equation model $[49,56]$, assuming Gaussian beam propagation [60] and that free-electrons are gained by multiphoton ionization (MPI) [61], avalanche ionization [27] and thermal ionization [30], and is lost by recombination [62]. 


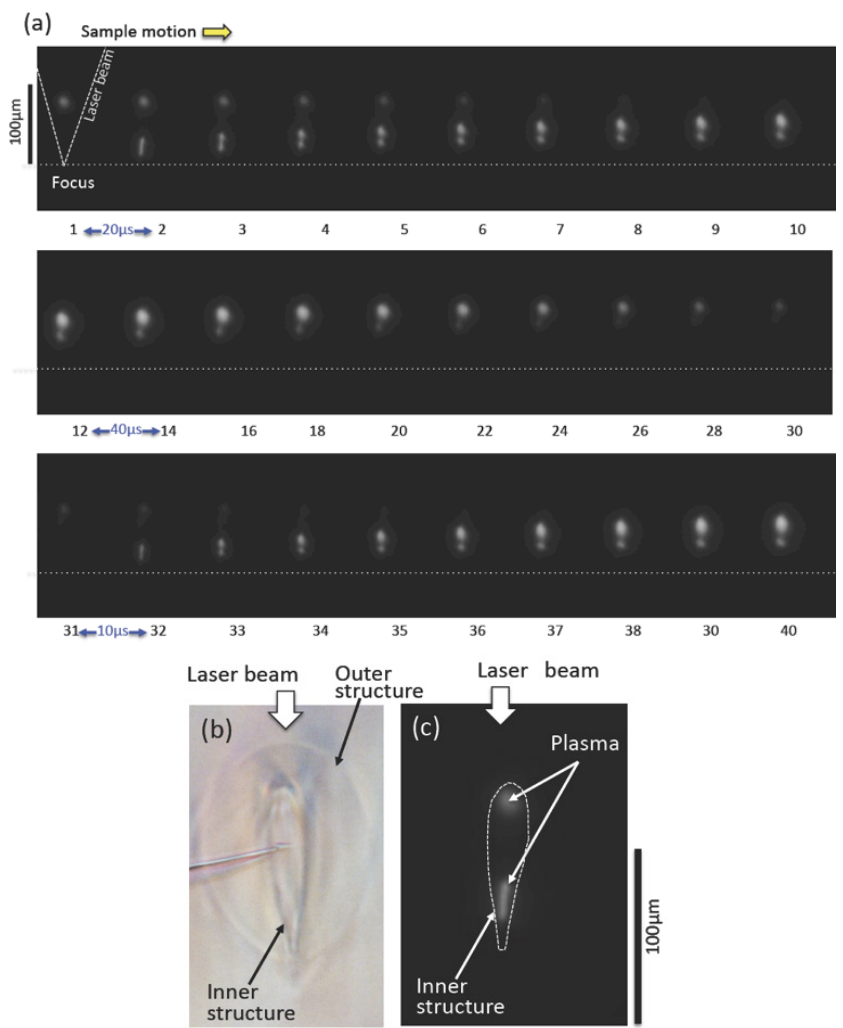

Fig. 7 (a) High-speed movies in internal melting of borosilicate glass by fs-laser taken at $5 \times 10^{4} \mathrm{f} / \mathrm{s}$ (frame numbers are relative). (b) Cross-section and (c) a snap shot of plasma superimposed to (b) ( $\mathrm{f}=1 \mathrm{MHz}$ and $\mathrm{Q}_{0}=2.5 \mu \mathrm{J}, \mathrm{v}=20 \mathrm{~mm} / \mathrm{s}$ ).

Figure 8 shows the variation of the axial temperature distribution $\mathrm{T}(0, \mathrm{z}, \mathrm{t})$ and the absorbed laser energy $\mathrm{p}(0, \mathrm{z}, \mathrm{t})$ in the plasma in the heat accumulation regime simulated based on the thermal conduction model coupled with the rate equation model [63]. In this simulation, it is assumed that the freeelectrons are generated by thermal ionizations in addition to multiphoton and avalanche ionization. The simulated values are relative, since the physical properties of glass were assumed to be constant, for simplicity. A small plasma generated near the focus moves toward the laser source as the number of the laser pulse $n$ increases in accordance with the experimental observation shown in Fig. 7. Such a plasma motion occurs, because the laser absorption $\mathrm{p}(0, \mathrm{z}, \mathrm{n})$ concentrates near the front face of the plasma to generate free-electrons by thermal ionization. The amplitude of the cyclic plasma motion increases as the number of the plasma cycle increases due to the increased heat accumulation (not shown here), providing the weld bead extended along the optical axis. This suggests that the plasma can be sustained even at locations far away from the focus where the contribution of MPI is negligible to make the laser absorption region much longer than $Z_{R}$ (Fig. 4). The free-electrons near the plasma front are mainly supplied by the thermal ionization to seed avalanche ionization in the heat accumulation regime.

\subsection{Thermal stress in glass welding}

Here a thermal stress model in laser welding of glass/glass is described in some detail with supplementary explanation of Ref. [20], because the effects of a free-surface of the molten pool on the thermal stress has never discussed before the advent of USL laser technology in the long history of welding technology.

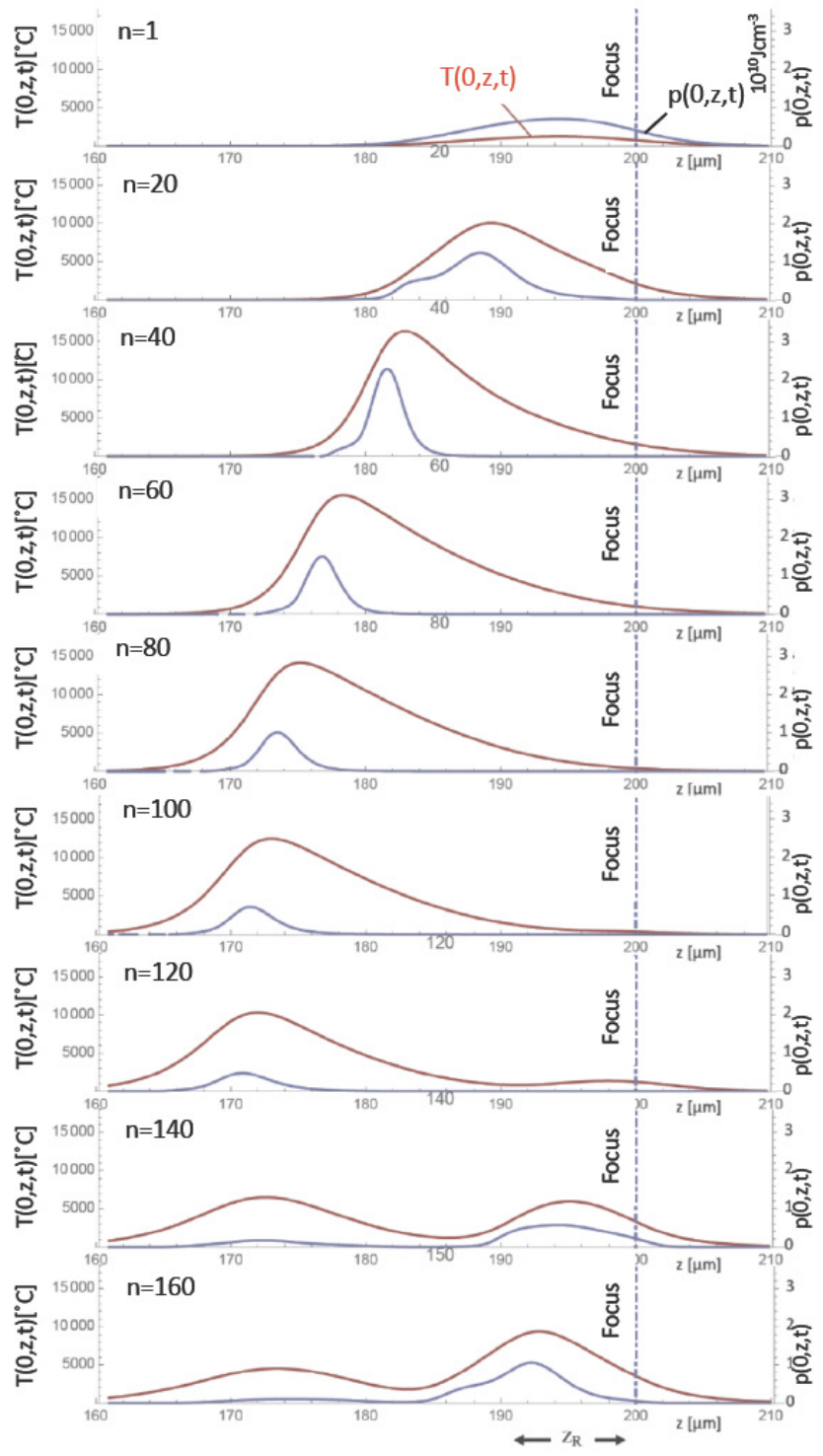

Fig. 8 Axial distribution of the specific absorbed laser energy $\mathrm{p}(0, \mathrm{z}, \mathrm{t})$ and plasma temperature $\mathrm{T}(0, \mathrm{z}, \mathrm{t})$ simulated at different pulse number $\mathrm{n}$ assuming $\tau_{\text {coll }}=10 \mathrm{fs}\left(\mathrm{f}=1 \mathrm{MHz}, \mathrm{Q}_{0}=4 \mu \mathrm{J}, \lambda=1064\right.$ $\left.\mathrm{nm}, \tau_{\mathrm{p}}=10 \mathrm{ps}, \mathrm{v}=20 \mathrm{~mm} / \mathrm{s}, \mathrm{D} 263\right)$ [63].

\section{(a) Thermal stress model}

Figure 9 schematically illustrates the thermal stress in an H-type restraint specimen [64] where the heating region A is thermally separated from the surrounding cold region $\mathrm{B}$, and $A$ and $B$ are connected to a rigid body $\left(S_{A}<<S_{B}\right.$ : $S_{A}$ and $\mathrm{S}_{\mathrm{B}}$ are the cross-sectional area of $\mathrm{A}$ and $\mathrm{B}$, respectively). Here the thermal stress $\sigma_{A}$ in $A$ is solely discussed, since the thermal stress $\sigma_{B}$ in $B$ is much smaller than $\sigma_{A}$ due to $S_{A}<<$ $\mathrm{S}_{\mathrm{B}}$. Figure 10 shows $\sigma_{\mathrm{A}}$ plotted vs. temperature $\mathrm{T}$ under the assumptions below for simplicity:

(i) glass is completely elastic with a constant Young modulus of $\mathrm{E}=\mathrm{E}_{0}$ in a temperature range of $\mathrm{T}_{0}<\mathrm{T}<\mathrm{T}_{\text {melt }}$, and plastic with $\mathrm{E}=0$ in $\mathrm{T} \geqq \mathrm{T}_{\text {melt }}$ so that the melt glass deforms freely where $T_{0}=$ room temperature and $T_{\text {melt }}=$ melting temperature, and

(ii) cracks are produced by the tensile stress since $\sigma_{\text {rup,c }}>>$ $\sigma_{\text {rup }, \mathrm{t}}[65]$ where $\sigma_{\text {rup }, \mathrm{c}}=$ compressive strength and $\sigma_{\text {rup }, \mathrm{t}}=$ 
tensile strength of glass. The thermal stress in laser welding of glass depends on whether or not the molten pool has a free-surface as shown below.
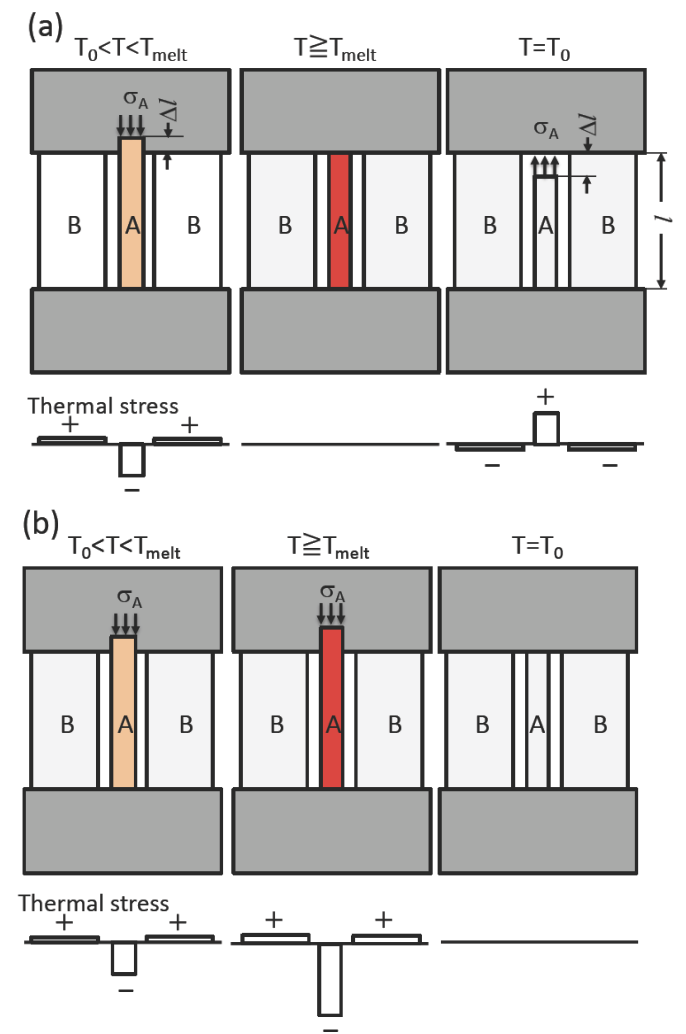

Fig. 9 Schematics of thermal stress induced in an H-type specimen with a length of $l$ at different temperatures where the molten pool has (a) a free-surface and (b) no free-surface. The tensile stress $\sigma_{\mathrm{A}}$ is produced when cooled down to $\mathrm{T}_{0}$, if $\mathrm{A}$ is plastically deformed at $\mathrm{T}=\mathrm{T}_{\text {melt }}(+$ : tensile stress, - : compressive stress $)$.

\section{(b) Molten pool having free-surface}

In glass welding where the molten pool has a free-surface, which corresponds to $\mathrm{CW}$ laser welding (Fig. 1a,b) or USP laser welding with air gap in Fig. 1c, the compressive stress $\sigma_{\mathrm{A}}$ is produced in the heating process of $\mathrm{T}_{0} \leqq \mathrm{~T}<\mathrm{T}_{\text {melt }}$, since the thermal expansion of $\mathrm{A}$ is restricted by $\mathrm{B} . \sigma_{\mathrm{A}}$ is given by $\left(\alpha=\right.$ CTE of the glass; $\left.\varepsilon_{\mathrm{A}}=-\Delta l /[l+\Delta l] \approx-\Delta l / l\right)$

$$
\sigma_{\mathrm{A}}=\varepsilon_{\mathrm{A}} \mathrm{E}_{0}=-\alpha \mathrm{E}_{0}\left(\mathrm{~T}-\mathrm{T}_{0}\right) \text {, }
$$

which increases along $\mathrm{O} \rightarrow \mathrm{P}$ in Fig. 10(a). It is noted that $\sigma_{\mathrm{A}}$ is completely released by the plastic deformation of the molten pool $(\mathrm{P} \rightarrow \mathrm{Q})$ on melting $\left(\mathrm{T}=\mathrm{T}_{\text {melt }}\right)$, because the molten glass having a free-surface deforms freely. Further temperature rise $\left(\mathrm{T}>\mathrm{T}_{\text {melt }}\right)$ keeps $\sigma_{\mathrm{A}}=0(\mathrm{Q} \rightleftarrows \mathrm{R})$.

In the cooling process $\left(\mathrm{T}<\mathrm{T}_{\text {melt }}\right)$ where elasticity is regained on solidification, the tensile stress $\sigma_{\mathrm{A}}$ given by

$$
\sigma_{\mathrm{A}}=\varepsilon_{\mathrm{A}} \mathrm{E}_{0}=\alpha\left(\mathrm{T}_{\text {melt }}-\mathrm{T}\right) \mathrm{E}_{0}
$$

increases along $\mathrm{Q} \rightarrow \mathrm{S}$. In the glass having large $\alpha$ like borosilicate glass, cracks are produced when $\sigma_{\mathrm{A}}$ reaches $\sigma_{\text {rup,t }}$ at $\mathrm{S}^{\prime}$. However, no cracks are produced in $\mathrm{A}$, if $\alpha$ is small enough to provide $\alpha\left(\mathrm{T}_{\text {melt }}-\mathrm{T}_{0}\right) \mathrm{E}_{0}<\sigma_{\text {rup,t, }}$, as shown by a blue line ( $\mathrm{Q} \rightarrow \mathrm{S}$ '). It is noted, however, that the weld joint strength is decreased, since the tensile stress $\sigma_{\text {resid }}=\alpha\left(T_{\text {melt }}\right.$ $-\mathrm{T}_{0}$ ) $\mathrm{E}_{0}$ (residual stress) is left in $\mathrm{A}$ at $\mathrm{T}=\mathrm{T}_{0}$ to decrease the weld strength, as is illustrated in Fig. 15. This suggests that a post annealing process is recommended even if cracks are suppressed in CW laser welding or USP laser welding with air gap, since the weld region has the residual tensile stress $\sigma_{\text {resid }}$ so that the weld joint strength is reduced or the thermal deformation of the weld joint can occur, as typically observed in metal welding process. This is the well-known mechanism of the shrinkage stress formation in $\mathrm{CW}$ laser welding having free surface in the molten pool $[12,13]$.

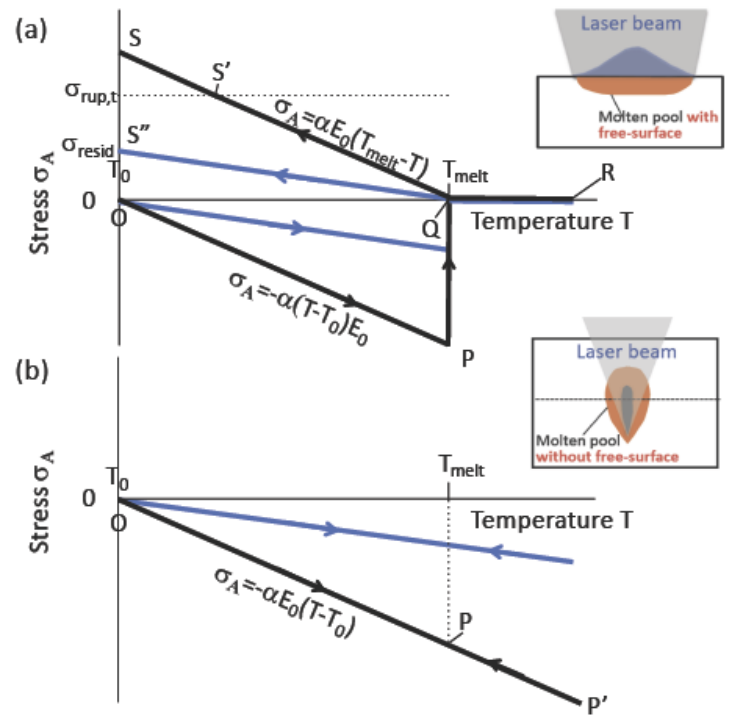

Fig. $10 \sigma_{A}$ vs. temperature with the molten pool having (a) freesurface (CW-laser) and (b) no free-surface (USP laser). Blue and black lines correspond to glass with smaller and larger CTE, respectively ( + : tensile stress, - : compressive stress).

It is concluded that the shrinkage stress in $\mathrm{A}$ is produced by the plastic deformation of the melt glass $(\mathrm{P} \rightarrow \mathrm{Q})$, if the molten pool has a free-surface. In other words, cracks or residual stress can be suppressed by preventing the plastic deformation of the melt pool.

\section{(c) Melt pool having no free-surface}

The molten pool having no free-surface is an "unexpected welding mode" in the conventional welding technology before the advent of USP laser welding. While $\sigma_{\mathrm{A}}$ increases linearly along $\mathrm{O} \rightarrow \mathrm{P}$ again, it continues to increase along $\mathrm{P} \rightarrow \mathrm{P}$ ' even after melting ( $\mathrm{T} \geqq \mathrm{T}_{\text {melt }}$ ) as shown in Fig. 10 (b), unless $\mathrm{B}$ is damaged by the thermal expansion of $\mathrm{A}$. This is because the molten pool having no free-surface cannot be plastically deformed by the isotropic pressure in the molten glass despite that the molten glass itself is plastic. It should be emphasized that no residual stress is thus produced when cooled down to room temperature so that the post annealing process is not needed, because the elastic deformation is reversible $\left(\mathrm{O} \rightleftarrows \mathrm{P}^{\prime}\right)$.

Figure 11 shows the weld bead strength $\sigma_{\text {rupt }}$ plotted vs. the averaged absorbed laser power $\mathrm{W}_{\mathrm{ab}}$ with Foturan glass, showing that $\sigma_{\text {rupt }}$ decreases with increasing $\mathrm{W}_{\mathrm{ab}}$ [51]. This is because the region B is partially damaged or weakened by the tensile thermal stress produced in heating process at excess values of $\mathrm{W}_{\mathrm{ab}}$.

The validity of the thermal stress model shown in Figs.9 and 10 was examined by focusing USP laser near the bottom surface of the tilted glass sample with the horizontal focus motion (Fig. 12). While no cracks are produced when the molten pool stays in the bulk glass [A]. Cracks are produced 
when the molten pool is exposed to the bottom surface to have a free-surface [B], verifying the model [20].

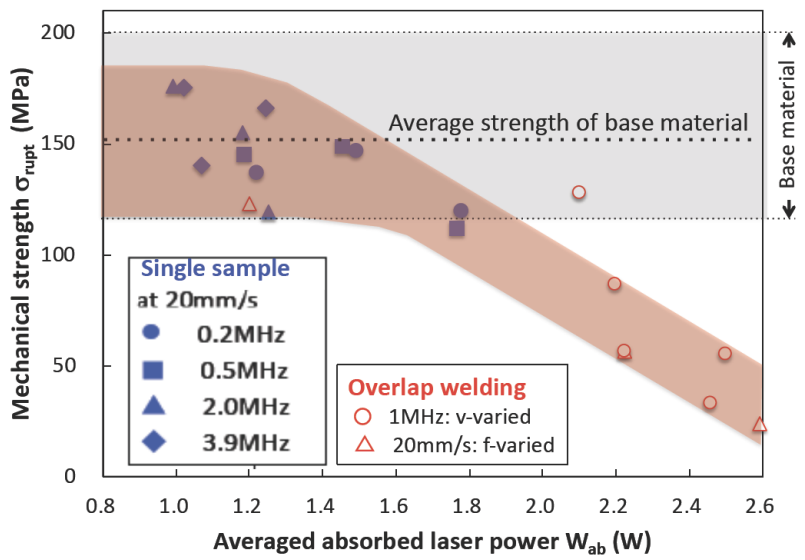

Fig. 11 Mechanical strength of internally melted single glass sample and overlap-weld joint plotted vs. average absorbed laser power $\mathrm{W}_{\mathrm{ab}}$ in Foturan glass.

It is noted that the molten pool having no free-surface can be also produced by ns-laser pulses in dissimilar welding of glass/metal $[66,67]$ or glass/Si [68], as will be described later. In this process the internal melt pool can be produced by the linear absorption process at metal or $\mathrm{Si}$, enabling crack-free welding as shown in Fig. 1(d).

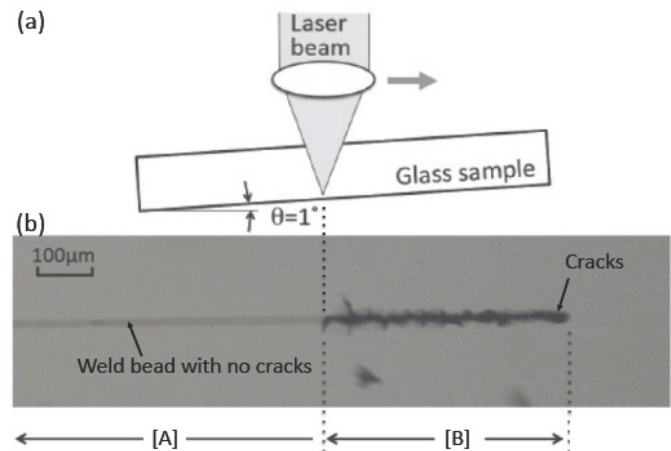

Fig. 12 (a) Experimental set up. (b) Result of laser-irradiation: [A] no cracks in internal melting, and $[\mathrm{B}]$ cracks are produced when the molten pool is exposed to the bottom surface $\left(\mathrm{f}=1 \mathrm{MHz}, \mathrm{Q}_{0}=\right.$ $1.6 \mu \mathrm{J})$.

\subsection{Gap bridging with non-optical contact (NOC)}

Optical contact (OC) is an ideal sample preparation to produce the molten pool having no free-surface for preventing the cracks or the residual tensile stress in USP laser welding of glass. In practical applications, however, it is not easy to realize OC across the interface having especially a large area or curved surface structure. While the mechanical force was applied to realize OC in the early work in USP laser welding $[17,68]$, the weld strength was significantly lowered especially when the applied force is nonuniform, because the nonuniform force provides the residual stress in the weld region. Recently the gap bridging with NOC in welding glass/glass has been reported by several groups $[36,69,71$, 72] as shown below.

Cvecek et al. found that a high temperature bulge is irreversibly produced by focusing USP laser near the glass plate's surface, and can bridge the gap of approximately up to $1 \mu \mathrm{m}$ in in different glass substrates including BF33, sodalime and fused silica (Fig. 13) [69]. The crack opening test showed the average bonding energy reaches $1.5 \sim 2 \mathrm{~J} / \mathrm{m}^{2}$, which corresponds to the value attained by the diffusion bonding at $800{ }^{\circ} \mathrm{C}$ [70]. The weld samples separated after welding showed the material come from the partner plate attached to the bulge surface, suggesting the glass substrates were joined strongly. The similar joining process was also shown by Bovatsek et al. [71], while twofold laser irradiations are necessary to achieve joining.

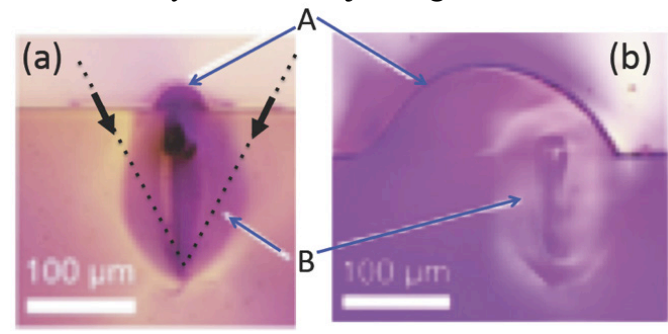

Fig.13 Cross-sections of pealed-off sample welded by the bulge in (a) soda-lime glass and (b) BF33. A: additional material come from partner plate and $\mathrm{B}$ : molten zone $\left(\mathrm{W}_{\mathrm{av}}=2 \mathrm{~W}, \tau_{\mathrm{p}}=10 \mathrm{ps}\right)$.

The gap can be bridged with filling by the molten glass generated within the glass plates. J. Chen et al. determined the bridgeable gap in the single-pass USP laser welding of fused silica using samples prepared precisely by an etching technology [36]. They showed that the overlap welding of glass plates having gap is classified into four groups: (A) plasma ablation, (B) HAZ (heat affected zone) ablation, (C) intermittently welded and (D) continuously welded (successful welding), as seen in the inset of Fig. 14. Figure 14 indicates the weld bead obtained at different values of gap $\mathrm{G}$ (depth of groove) and pulse energy $\mathrm{Q}_{0}$ at $\mathrm{f}=400 \mathrm{kHz}$ with the fixed laser focus position in fused silica, showing that the pulse energy $\mathrm{Q}_{0}$ needed for the continuous welding (D) increases linearly with increasing the gap.

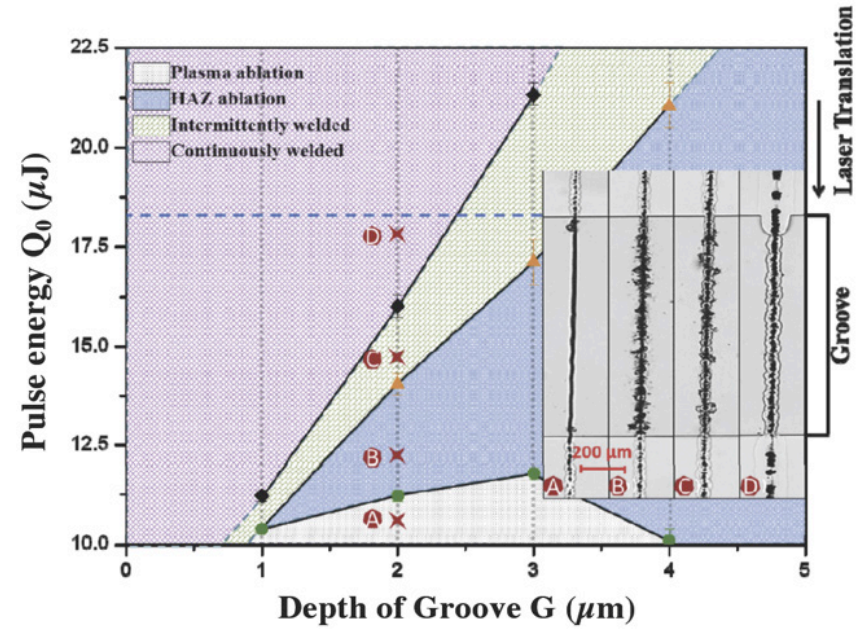

Fig.14 Parameter map illustrating the classification of weld results with varying pulse energy $\mathrm{Q}_{0}$ and gap distance $\mathrm{G}$ in fused silica. The inset shows four different welding patterns ( $\mathrm{f}=400$ $\mathrm{kHz}, \lambda=1030 \mathrm{~nm}, \tau_{\mathrm{p}}=5.9 \mathrm{ps}$ ) (with courtesy of J. Chen et al.).

Richter et al. also determined the bridgeable gap in the single-pass USP laser welding of fused silica with NOC at an average laser power of $\mathrm{W}_{\mathrm{av}}=8 \mathrm{~W}$ [55]. It is seen that the gap up to approximately $3 \mu \mathrm{m}$ can be bridged, which is comparable to Ref.[36]. They also compared the weld joint strength between OC and NOC glass samples, showing that NOC samples provide $10 \sim 15 \%$ smaller mechanical 
strength than that of OC (Fig. 15). The thermal stress model discussed in Section 4.3(b) [20] suggests that the decrease in the weld strength of NOC is caused by the residual tensile stress $\sigma_{\text {resid }}$ shown in Fig. 10(a), because the molten pool in NOC samples has a free-surface.

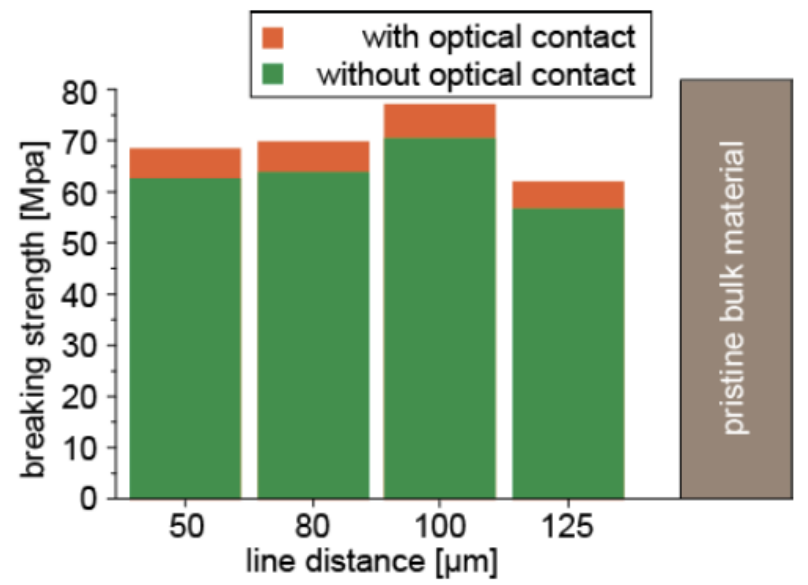

Fig. 15 Comparison of breaking strengths between OC and NOC laser-welded fused silica samples welded at different values of linespacing in comparison with the pristine bulk material (with courtesy of Richter et al.)

In the above two gap bridging examples [36,55], we should note that fused silica was used, whose CTE is small enough to avoid cracking even by $\mathrm{CW}$ laser welding (Section 3). In order to demonstrate the effect of the free-surface of the molten pool produced by the gap in glass having large CTE on crack formation, an experiment was carried out using variable gap $\mathrm{G}$ in borosilicate glass $\left(\mathrm{CTE}=72 \times 10^{-7}\right.$ $\mathrm{K}^{-1}$ ) [20]. As shown in Fig. 16, cracks are produced in $\mathrm{G}>$ $0.26 \mu \mathrm{m}$, although the gap can be geometrically bridged at least up to $G=1.2 \mu \mathrm{m}$ (left edge of Fig. 16b). This suggests that cracks are produced by the shrinkage stress, even if the gap is geometrically bridged in a single-pass welding of glass having large CTE.

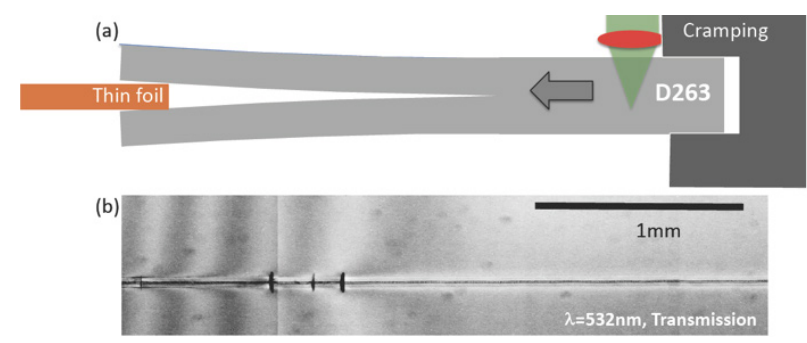

Fig. 16 (a) Setup for welding glass substrates with variable gap in single-pass USP laser welding of D263. (b) Transmission images of the laser welded sample observed at 532nm are shown $(\lambda=1064$ $\mathrm{nm}, \tau_{\mathrm{p}}=10 \mathrm{ps}, \mathrm{Q}_{0}=1.6 \mu \mathrm{J}, \mathrm{f}=1 \mathrm{MHz}, \mathrm{v}=20 \mathrm{~mm} / \mathrm{s}$ ).

Recently, H. Chen et al. developed a novel USP laser welding procedure that allows bridging of large gap in sodalime glass having CTE as large as $90 \times 10^{-7} \mathrm{~K}^{-1}$ [72]. They used a galvanometer for multiple-scanning of a focused laser spot coaxially with the outer radius of $\mathrm{R}$ to generate a horizontally extended molten pool as shown in Fig. 17. The molten glass filled the gap as large as $\mathrm{G}=10 \mu \mathrm{m}$ (corresponding to natural stack), which was reduced to the final gap of $\mathrm{G}_{\mathrm{f}}=$ $2.8 \mu \mathrm{m}$ after welding without visible cracks. It is considered that the crack-free welding is realized using this welding system, because the coaxial laser spot-scanning generates a radially descending gentle temperature distribution in the molten pool in the gap space, so that a molten pool surrounded peripherally by the solidified glass (molten pool having no free-surface) is produced. This is contrastive to the case of the single pass welding $[20,36,55]$ where the whole gap space is filled with melt glass (molten pool with a free-surface: Fig. 16). However, we should note that a negative pressure could be produced in the molten zone since the final gap space of $G_{f}$ has to be filled with the limited amount of the melt glass volume, resulting possibly in the decrease in weld joint strength or even cracks in the weld region, if the final gap is not small enough. Further study is needed to increase the bridgeable gap without cracks or decrease in the joint strength.

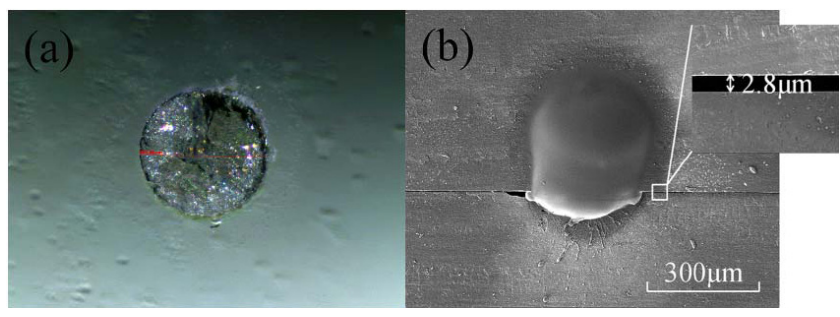

Fig. 17 Microstructure of the weld area with radius $R=0.3 \mathrm{~mm}(G$ $=10 \mu \mathrm{m}$ ). (a) Top view by a transmission microscope and (b) the transvers SEM image of the weld bead showing final gap of $\mathrm{G}_{\mathrm{f}}=$ $2.8 \mu \mathrm{m}\left(\lambda=1064 \mathrm{~nm}, \tau_{\mathrm{p}}=10 \mathrm{ps}, \mathrm{Q}_{0}=12 \mu \mathrm{J}, \mathrm{f}=1 \mathrm{MHz}\right)$. Reprinted with permission from [72]. C2019 by The Optical Society of America.

\subsection{Applications of USP laser welding of glass}

The development of USP laser glass welding technology has been driven by its excellent weld properties including hermeticity, minimized weld bead size and high joint strength attained at high throughput, which are important in industrial applications including microelectronics, optics and medical. Here some published applications of USP laser welding of glass are introduced, while most of them are of laboratory demonstration at the moment.

One of the most attractive applications using USP laser is fabrication of 3D microfluidic structures inside the glass combined with selective etching process $[15,16,73]$. However, the drawback in this process is the extremely low etch rate (typically $300 \mu \mathrm{m} / \mathrm{h}$ in $\mathrm{KOH}$ [73]), and thus even a few days are needed for completing the development of a microstructure. The drawback can be removed by an appropriate combination of 2D planer structures with USP laser welding for manufacturing embedded $3 \mathrm{D}$ structures. A rapid and reliable 3D fabrication method of glass microfluidic device was developed where glass plates with 2D planar channels produced by laser assisted selective etching [74] or micromachining by laser ablation [75] are combined with direct laser welding. By this approach, fully-functional microfluidic device can be fabricated in less than two hours [75]. The process provides much higher bonding strength than conventional adhesive bonding methods like polydimethylsiloxane (PDMS) devices [76]. This fabrication method has potential to be used for glass microfluidic devices in harsh environments where PDMS microfluidic devices cannot endure.

Recently, a novel packaging process using USP laser welding has been developed for assembling an implantable 
blood pressure sensor. The sensor contains a membrane type, passive device using the change in the capacitance caused by the membrane deformation due to blood pressure [77]. Components of the sensor such as inductors and capacitors were fabricated on two quartz glass substrates, which were welded into a single package using ps pulse laser in heat accumulation regime. The weld bead size of $100 \mu \mathrm{m}$ allows a drastic reduction in the sensor size. After welding the sensors are cut by the same laser to separate from the glass wafer to the designed size $(4 \times 16 \times 0.75 \mathrm{~mm})$, which is implantable into the femoral artery.

A novel assembling procedure for the endcap of optical fibers with further downsized welding [78] has been developed using fs pulse laser to increase the damage threshold of the optical fiber. In this process, the glass is melted with extremely high spatial resolution by the optical filamentation which arises from a balance between Kerr self-focusing and plasma defocusing [79]. The major benefit of using filamentation for welding is that the heating is strictly confined to a very narrow filament region with little effect on the core regions. In order to evaluate the weld joint strength for standard optical fiber, welding was performed between silica rod with $240 \mu \mathrm{m}$ diameter, for instance, and glass plate with OC where an annular welding was performed by 57 passes of spaced $2 \mu \mathrm{m}$ apart in a spiral motion to provide $10 \mu \mathrm{m}$ diameter of the optical transmission window (core) as shown in Fig. 18. The tensile test showed the weld joint strength of approximately $10 \mathrm{MPa}$ was obtained. The method has been demonstrated for not only above standard fiber but microstructured optical fiber (MOF), which is used in the generation of supercontinuum [80]. In MOF the endcaps can also seal the air-holes and thus prevent their progressive degradation due to $\mathrm{OH}$ diffusion inside the glass. In assembling the endcap for MOF, weld lines were successfully written by ten weld lines spaced by $1 \mu \mathrm{m}$ in the outer narrow ring ( $25 \mu \mathrm{m}$ thickness) between the air-hole ring and the fiber circumference.

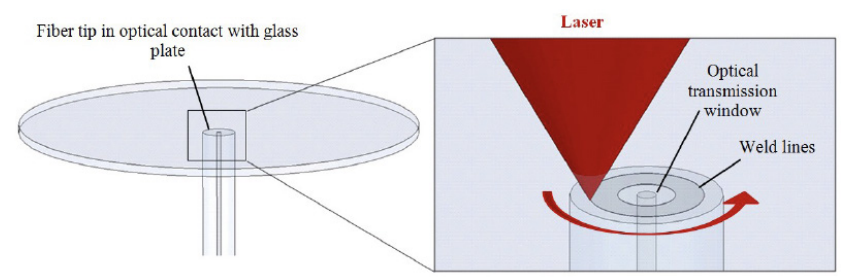

Fig.18 Illustration of USP laser welding of the tip) to a glass plate $\left(\tau_{\mathrm{p}}=70 \mathrm{fs}, \lambda=787 \mathrm{~nm}, \mathrm{f}=250 \mathrm{kHz}, \mathrm{Q}_{0}=0.6 \mu \mathrm{J}, \mathrm{v}=0.2 \mathrm{~mm} / \mathrm{s}\right)$. Reprinted with permission from [78]. (C2013 by The Optical Society of America.

An USP laser welding procedure for assembling a protection cap of quartz glass has been developed by Trumpf Laser $\mathrm{GmbH}$, which prevents dirt from coming into contact with the end surfaces of the fibers with a core diameter of approx. 0.1 $\mathrm{mm}$, for instance [81]. Previously the lid of the protective cap was bonded by glue, which does not remain cleanly on the edge of the glass but some tiny glue droplets stray onto the inner wall of the cap in the glue-handling process, leading to a high reject rate in production. The economic effects of the new glasswelding process are that optical transparency is no longer obstructed by contamination without long-term embrittlement of adhesive, providing much more durable solutions. The process has been industrialized since 2016 in their own manufacture of laser light cables with a plug having glass lid thickness up to $6 \mathrm{~mm}$, which transports average laser power up to $6 \mathrm{~kW}$ to a robot for the welding and/or cutting of metal sheets.

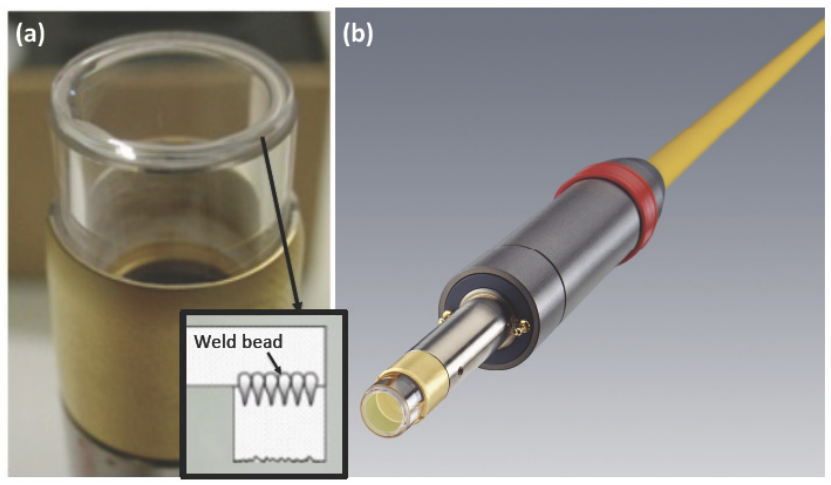

Fig. 19 (a) Glass protection cap assembled by USP laser welding. Approximate 700 pieces have been produced by welding since 2016. (b) The silica fibers have a core diameter ranging from 100 to $600 \mu \mathrm{m}$ (with courtesy of Trumpf Laser GmbH).

\section{Laser welding dissimilar materials}

Molten pool having no free-surface can be also produced in laser welding of dissimilar materials (glass/metal or glass/Si), if the substrates are in close contact. In this process, the laser energy is first absorbed at the surface of the metal (or $\mathrm{Si}$ ) substrate via linear process and then the glass is melted by the transfer of the heat and the melt from the metal (or $\mathrm{Si}$ ). This means that the molten pool having no free-surface (internal melting: Fig. 1d) can be produced using not only USP laser but ns pulse laser, enabling crack-free welding.

\subsection{Glass/metal welding}

Glass/metal samples in close contact can be laser-welded not only with non-heat accumulation regime $[66,67,82]$ but with heat accumulation regime [84-87]. Ozeki et al. compared the joint strength of glass/ $\mathrm{Cu}$ welding between fs laser $\left(\tau_{\mathrm{p}}=130 \mathrm{fs}\right)$ and $\mathrm{ns}\left(\tau_{\mathrm{p}}=600 \mathrm{~ns}\right)$ laser at a pulse repetition rate of $\mathrm{f}=1 \mathrm{kHz}$ where heat accumulation can be neglected [67]. It is noted that the laser pulse energy needed for welding by fs pulse is more than two-orders smaller hence with smaller HAZ than ns pulse, since the fs pulse energy can be directly absorbed in the bulk glass through the filaments (Fig. 20) [83]

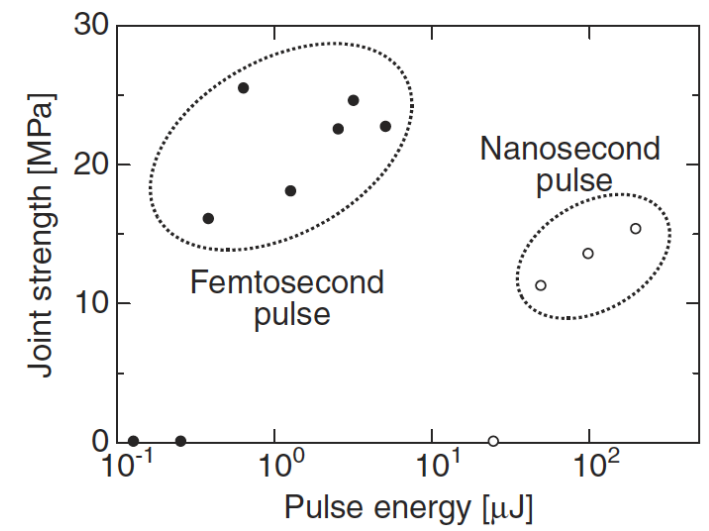

Fig. 20 Weld joint strength plotted vs. pulse energy for joining nonalkali glass $/ \mathrm{Cu}$ at $\mathrm{f}=1 \mathrm{kHz}$. $\bullet$ : fs pulses $\left(\lambda=800 \mathrm{~nm}, \tau_{\mathrm{p}}=130 \mathrm{fs}\right)$. $\circ:$ ns pulses $\left(\lambda=527 \mathrm{~nm}, \tau_{\mathrm{p}}=600 \mathrm{~ns}\right)$ [67]. Copyright (2008) The Japan Society of Applied Physic. 
Heat accumulation makes glass/metal welding faster and more reliable. Carter et al. [85] demonstrated the dissimilar material welding with close contact with a variety of material combinations between transparent material (fused silica, borosilicate glass and sapphire) and opaque material $(\mathrm{Cu}, \mathrm{Al}$, stainless steel and $\mathrm{Si}$ ) with different $\mathrm{CTE}$ mismatches of $\mathrm{R}_{\mathrm{CTE}}\left(\mathrm{R}_{\mathrm{CTE}}=\mathrm{CTE}_{\text {metal }} / \mathrm{CTE}_{\text {glass }}\right)$ in heat accumulation regime. It is noted that successful welding was obtained with different $\mathrm{R}_{\mathrm{CTE}}$ ranging from $\mathrm{R}_{\mathrm{CTE}}=3.4(\mathrm{Al} 6082$ / $\mathrm{BK} 7)$ to as large as $\mathrm{R}_{\mathrm{CTE}}=47.1\left(\mathrm{Al} 6082 / \mathrm{SiO}_{2}\right)$ [86]. Figure 21 shows the replotted shear test results where $\mathrm{P}_{\mathrm{S}}\left(\mathrm{V}_{0}\right)$ represents the probability of surviving the applied shear force. Interestingly the similar $\mathrm{P}_{\mathrm{S}}\left(\mathrm{V}_{0}\right)$ results were obtained between $\mathrm{R}_{\mathrm{CTE}}=3.4$ and $\mathrm{R}_{\mathrm{CTE}}=47.1$, suggesting that the large mismatch $\mathrm{R}_{\mathrm{CTE}}$ can be compensated if the molten pool having no free-surface is produced.

Based on a potential industrial requirement for thermal cycling, thermal cycle tests were carried out between $+90^{\circ}$ and $-50{ }^{\circ} \mathrm{C}\left(1^{\circ} \mathrm{C} \mathrm{min}^{-1}, 6\right.$ cycles $)$, and after the thermal cycling a $20 \mathrm{~N}$ shear force was applied to determine if the weld retains sufficient strength [86]. The weld joint of Al6082/ BK7 $\left(R_{\mathrm{CTE}}=3.4\right)$ survived the thermal cycle tests, although cracks are produced to have potentially reduced the strength of the bonds after thermal cycling. In the weld joint of $\mathrm{Al} 6082 / \mathrm{SiO}_{2}\left(\mathrm{R}_{\mathrm{CTE}}=47.1\right)$, however, none of the weld survived thermal cycling, while it can survive a thermal cycle in the welding process to provide joint strength comparable to BK7 $\left(\mathrm{R}_{\mathrm{CTE}}=3.4\right)$ (Fig. 21)

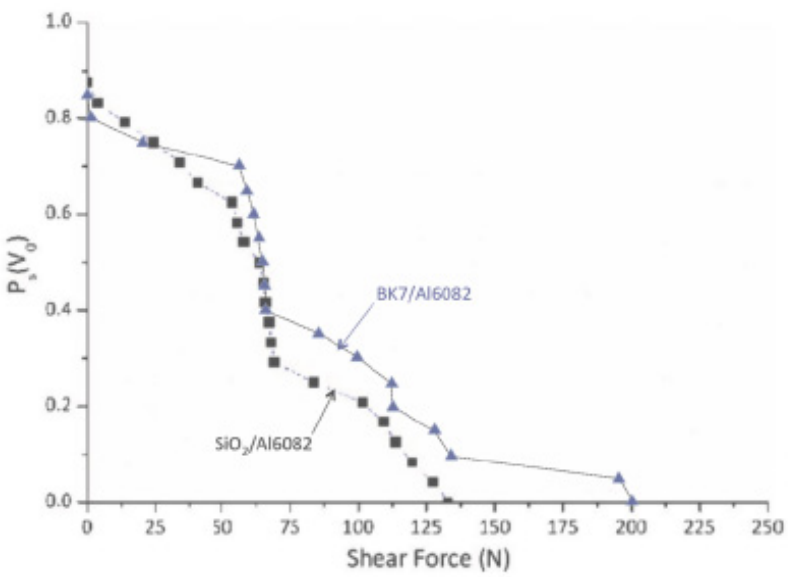

Fig. 21 Weibull shear test results for laser welded A16082 / BK7 $\left(\mathrm{R}_{\mathrm{CTE}}=3.4\right)$ and $\mathrm{Al} 6082 / \mathrm{SiO}_{2}\left(\mathrm{R}_{\mathrm{CTE}}=47.1\right)$ at $6.55 \mathrm{~W}$ and $6.13 \mathrm{~W}$, respectively (with courtesy of Carter et al.).

Ciuca et al. analyzed in detail the ps laser-welded structure of $\mathrm{SiO}_{2} / \mathrm{Al}$ in the heat accumulation regime (Fig. 22) [87]. It is noted that the $\mathrm{Al}$ substrate is depressed at the interface, suggesting that $A$ l surface at the interface is heated above $T_{B}$, and the molten $\mathrm{Al}$ flows into glass region by the evaporation recoil pressure to produce $\mathrm{SiO}_{2} / \mathrm{Al}$ mixture. Such a melt pattern is typical in dissimilar welding by USP laser, as is also observed in glass/Si welding later (Fig. 24) [88]. Extensive reactions in the weld zone are observed, which include nanocrystalline $\mathrm{Si}$, transitional alumina phases and crack-like keyhole presumably caused by large CTE difference between $\mathrm{SiO}_{2}$ and $\mathrm{Al}$. It is rather surprising that dissimilar materials of large CTE mismatch of $\mathrm{R}_{\mathrm{CTE}}=47.1$ can be welded by surviving the thermal cycle in the welding process, despite that crack-like keyhole is produced, which appears to be cured by filling with the melt glass. This suggests that the plastic deformation of $\mathrm{Al}$ occurs in solidification of $\mathrm{Al}$ unlike the case of glass/glass welding. It should be also noted that the plastic deformation is limited to a small region, because the total volume of the weld region does not change in solidification process due to the molten pool having no freesurface. However, the post process annealing is recommended for removing the residual stress in welding of glass/metal having large $\mathrm{R}_{\text {CTE }}$. Further study is needed for optimization of glass/metal welding having large $\mathrm{R}_{\mathrm{CTE}}$.

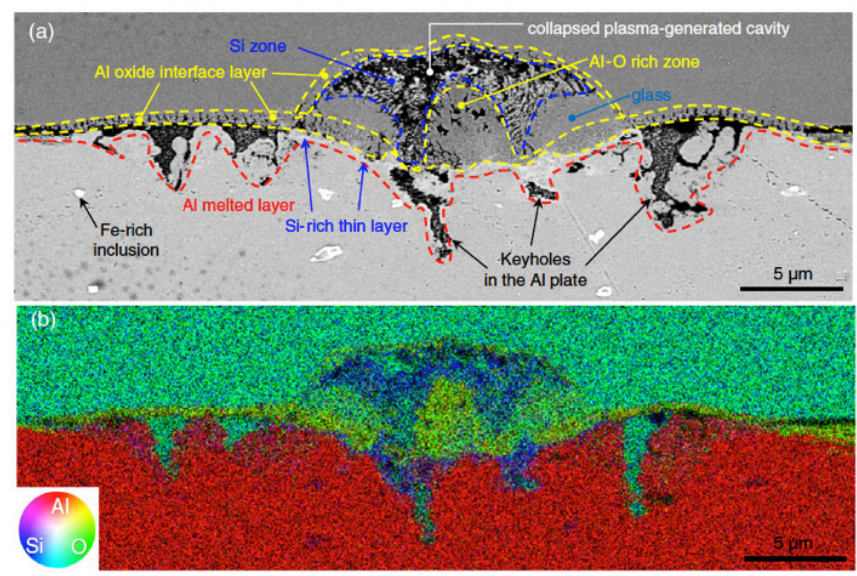

Fig. 22 Typical cross section of a single weld track in heat accumulation regime, showing (a) an annotated BSE (backscattered electron)-SEM image of the main beam interaction area and surrounding area and (b) a corresponding color coded Al, Si, O EDS (energy-dispersive X-ray spectroscopy) map of the same region (with courtesy of Ciuca et al.).

\subsection{Glass/Si welding}

Laser welding of glass/Si has been reported by many authors $[85,88-90]$ based on due to smaller $\mathrm{R}_{\mathrm{CTE}}$ along with great interest in industrial applications.

\section{(a) Prevention of melt Si splash}

In glass/Si welding, a critical problem is melt $\mathrm{Si}$ splash at high pulse energy caused by an excess evaporation recoil pressure exerting on the molten Si layer at the interface, resulting in the severely deteriorated weld quality [88]. While the molten metal splash also occurs in glass/metal welding at excess laser pulse energy [66], the melt splash in glass/Si is more violent than glass/metal. This is because the laser absorption coefficient $\alpha_{\mathrm{Si}}$ of $\mathrm{Si}$ increases many orders of magnitude by the temperature rise [91,92], resulting in further temperature rise at the very surface of Si substrate unlike the case of metal.

The melt splash of Si is affected by the duration $\tau_{\mathrm{p}}$ and the wavelength $\lambda$ of the laser pulse. The local temperature rise tends to occur more violently by ns pulses than USP laser, because $\alpha_{\mathrm{Si}}$ is increased by the temperature rise [91,92] to provide the stronger evaporation recoil pressure during ns pulse, while the temperature rise occurs after the pulse in USP lasers. It should be also noted that $\alpha_{\mathrm{Si}}$ increases as $\lambda$ becomes shorter [93], making the surface temperate of $\mathrm{Si}$ substrate higher. Figure 23 compares the surface appearance of the laser-irradiated glass/Si sample between two extreme conditions: $\mathrm{ns}$ at $\lambda=532 \mathrm{~nm}$ and ps at $\lambda=1064 \mathrm{~nm}$. Although significant melt $\mathrm{Si}$ splash occurs with ns at $\lambda=532$ $\mathrm{nm}$, no splash is observed with ps at $\lambda=1064 \mathrm{~nm}$. 

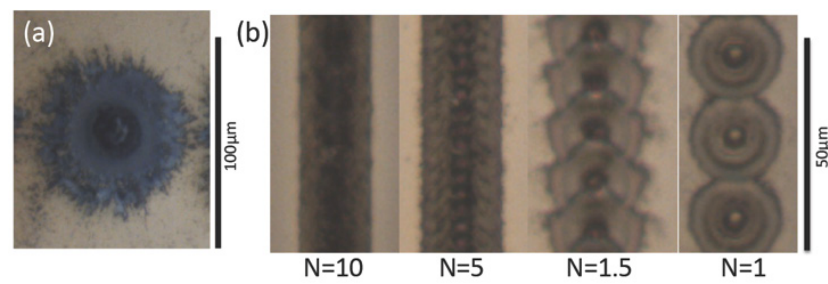

Fig. 23 Appearance of Borofloat 33/Si irradiated by (a) $\lambda=532$ $\mathrm{nm}, \tau_{\mathrm{p}}=120 \mathrm{~ns}$, (b) $\lambda=1064 \mathrm{~nm}, \tau_{\mathrm{p}}=10 \mathrm{ps}$.

Nordin et al. compared the shear strength of the glass/Si joint with spot welding (separated laser spots) at different $\tau_{\mathrm{p}}$ (ns vs. ps) and $\lambda$ (532 nm vs. $1064 \mathrm{~nm}$ ) [90]. They showed that $1064 \mathrm{~nm}$ and ps pulses provide higher joint strength than $532 \mathrm{~nm}$ and ns pulses, respectively, in accordance with Fig. 23 , suggesting the difference in the weld joint strength is attributed to the difference in splash tendency, while their explanation is somewhat different. Interestingly it was also shown that the combination of ps pulse and $\lambda=1064 \mathrm{~nm}$ provides the joint strength of spot welding as high as approximately $200 \mathrm{MPa}$.

\section{(b) Welding in heat accumulation regime}

Welding speed can be increased in glass/Si in heat accumulation regime at higher pulse repetition rates [88]. In the heat accumulation regime, the laser energy is first absorbed in the Si substrate by linear absorption process at the laser intensity below the threshold of MPI of the glass similarly to glass/metal welding [87]. Then the glass region is melted by the transfer of the heat and the hot melt from the Si side, producing the glass/Si mixture where the laser energy can be linearly absorbed due to the lowered band gap of glass $/ \mathrm{Si}$ mixture as shown in Fig. 24. In this process, the melt $\mathrm{Si}$ flows into the glass region along the curved solid Si surface smoothly so that the melt Si splash is avoided.

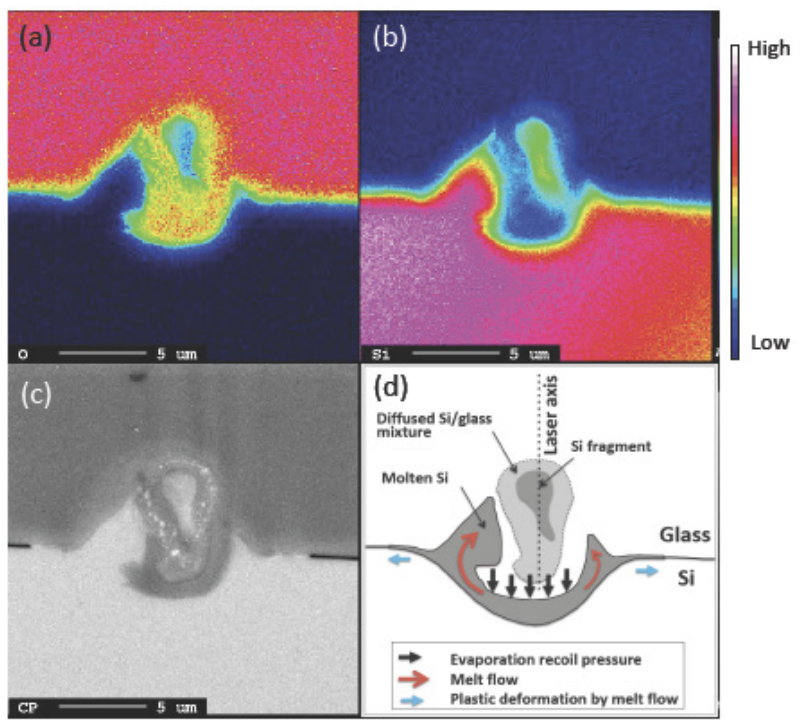

Fig. 24 Cross-section of welded D263/Si by ps pulses $(\mathrm{N}=14)$. Element analysis of (a) O and (b) Si. (c) SEM. (d) Schematics illustrating the melt Si flow. Blue arrows show plastic deformation of the melt $\mathrm{Si}$ at the interface by the recoil pressure of evaporation ( $\mathrm{f}=2 \mathrm{MHz}, \mathrm{Q}_{0}=2 \mu \mathrm{J}, \tau_{\mathrm{p}}=20 \mathrm{ps}$ and $\mathrm{v}=2 \mathrm{~m} / \mathrm{s}$ ).

It should be emphasized that the extremely high welding speed can be attained in glass/Si welding at high pulse repetition rates. This is because the laser energy is absorbed in a very thin molten region $\mathrm{h}(\mathrm{h}<10 \mu \mathrm{m})$ around the interface [88]. Figure 25 shows the weld joint strength of Borofloat $33 / \mathrm{Si}$ at $\mathrm{f}=0.5$ and $2 \mathrm{MHz}$ plotted vs. the pulse number in a melt region $\mathrm{N}(=\mathrm{df} / \mathrm{v} ; \mathrm{d}=$ melt diameter, $\mathrm{f}=$ pulse repetition rate and $\mathrm{v}=$ welding speed). The weld joint strength of $50 \mathrm{MPa}$ is maintained even at as small as $\mathrm{N}=7$ with $\mathrm{h} \approx 10 \mu \mathrm{m}$, which is much smaller than typical glass/glass welding (e.g. $\mathrm{N} \approx 1500$ and $\mathrm{h} \approx 70 \mu \mathrm{m}$ in Fig. 4), enabling extremely high welding speed. It is also noted that welding speeds even faster than $2 \mathrm{~m} / \mathrm{s}$ (corresponding to joining rate $\approx 1 \mathrm{~cm}^{2} / \mathrm{s}$ ) are possible using higher pulse repetition rate because of $\mathrm{v} \propto \mathrm{f}$.

While the weld joint strength $50 \mathrm{MPa}$ shown in Fig. 25 is high enough for packaging applications, we should note that $50 \mathrm{MPa}$ is significantly lower than the values attained in Ref.[89]. This could be attributed to the plastic deformation of the molten Si region along the interface (Fig. 24d) based on the thermal stress model.

Thanks to its high spatial resolution and high throughput, glass/Si welding technology can be applied to wafer level packaging, for instance. Since the laser-welded joint is strong enough for vacuum sealing, the welded sample can be singulated along the street by a standard mechanical dicer as shown in Fig. 26. While anodic bonding [2,94] has been widely used for joining glass/Si since its invention, it has disadvantages having no spatial resolution and requiring high temperature heating for long time under high electric field. On the other hand, the USP laser welding of glass/Si provides high spatial resolution without pre- and post-heating and electric field.

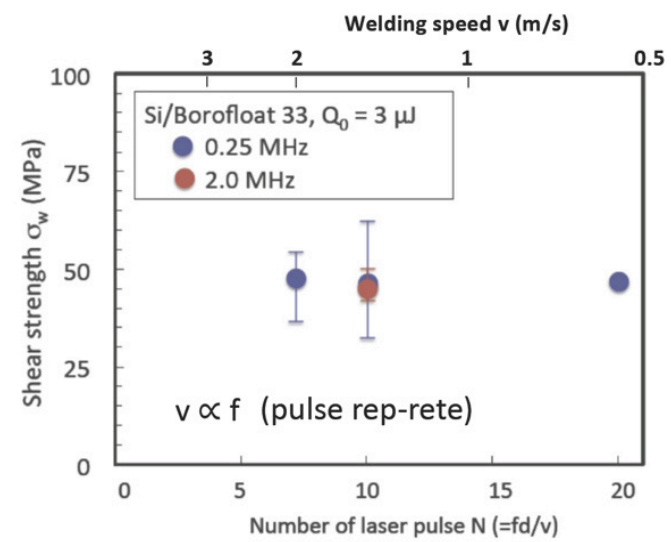

Fig. 25 Shear strength of laser-welded Borofloat 33/Si sample plotted vs. $\mathrm{N}(=\mathrm{fd} / \mathrm{N})$ and $\mathrm{v}$ at $\mathrm{f}=0.25 \mathrm{MHz}$ and $\mathrm{f}=2 \mathrm{MHz}\left(\tau_{\mathrm{p}}=20 \mathrm{ps}\right.$, $\left.\mathrm{Q}_{0}=3 \mu \mathrm{J}\right)$.

\section{Summary and outlook}

Advances of laser welding technology of glass including glass/glass and dissimilar welding (glass/metal or glass/Si) in the past two decades has been overviewed. Table 1 summarizes briefly the present status of CW and USP laser welding of glass/glass in terms of usable lasers, laser absorption process, molten pool property, weldable glass, residual stress, gap tolerance, weld bead size and future tasks.

CW lasers can be used for macroscopic welding of glass having small CTE like fused silica. Then post process annealing is recommended, since the molten pool having freesurface produces residual stress due to the molten pool 
having free-surface caused by linear absorption process. Future tasks of $\mathrm{CW}$ laser welding are technical developments including higher throughput and the process control [8] for process automation.

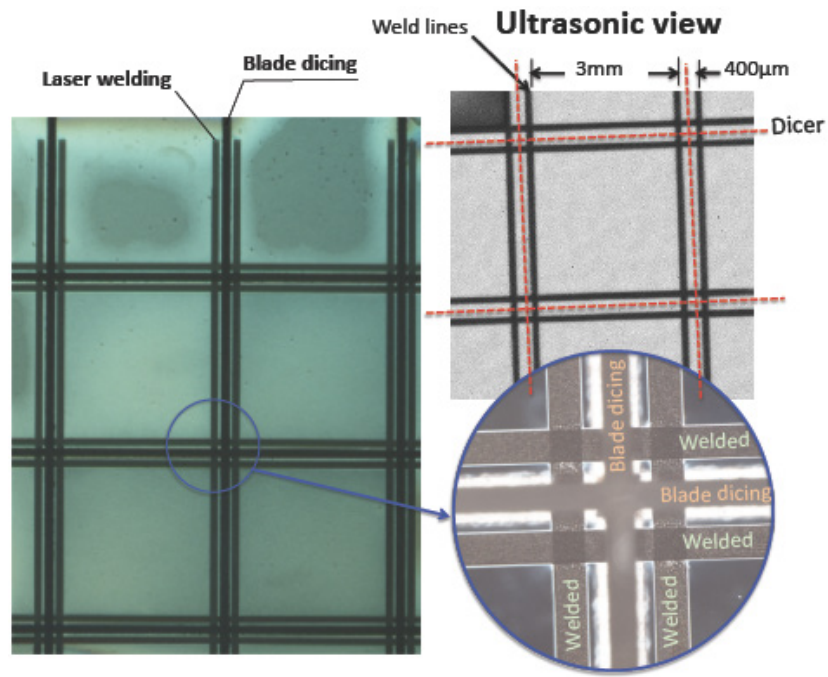

Fig. 26 Laser welded grid pattern in $\mathrm{Si} /$ Pyrex at $\mathrm{f}=2 \mathrm{MHz}$ and $\mathrm{Q}_{0}$ $=1 \mu \mathrm{J}$. Weld line of width $180 \mu \mathrm{m}$ consists of 20 weld lines. (a) Appearance of sample singulated by a standard dicer. (b) Ultrasonic examination. (c) Magnified picture of diced sample.

USP laser has realized crack-free glass welding independently of CTE of glass along with drastic downsizing, since the molten pool without free-surface produced by nonlinear absorption process provides no residual stress in the weld bead. In order to move USP laser welding closer to an industrially viable technology, however, systematic study of parameter space for welding is still needed, since there are a lot of parameters influencing the weld quality, which include pulse duration $\tau_{\mathrm{p}}$, wavelength $\lambda$, pulse energy $\mathrm{Q}_{0}$, pulse repetition rate $f$, translation speed $v, N A$ of focusing optics, and focus position [86]. Further downsizing of the weld bead is

Table 1 Comparison between CW and USP lasers in glass/glass welding.

\begin{tabular}{|c|c|c|c|}
\hline & CW laser welding & USP laser welding \\
\hline \multirow{2}{*}{$\begin{array}{l}\text { Lasers } \\
\text { for weld- } \\
\text { ing }\end{array}$} & $\tau_{\mathrm{p}}$ & & $\begin{array}{l}\text {-fs or ps laser pulses at high } \\
\text { pulse repetition rates }\end{array}$ \\
\hline & $\lambda$ & $\begin{array}{l}\text {-Opaque to glass } \\
\text { (Typically } 10.6 \mu \mathrm{m} \text { ) }\end{array}$ & -Transparent to glass \\
\hline \multicolumn{2}{|c|}{ Absorption by } & -Linear process & -Non-linear process \\
\hline \multicolumn{2}{|c|}{ Molten pool has } & -Free-surface & -No free-surface \\
\hline \multicolumn{2}{|c|}{ Weldable glass } & $\begin{array}{l}\text {-Limited to low } \\
\text { CTE glass }\end{array}$ & $\begin{array}{l}\text {-Any glass independently } \\
\text { of CTE }\end{array}$ \\
\hline \multicolumn{2}{|c|}{ Residual stress } & $\begin{array}{l}\text {-Residual stress is } \\
\text { produced (post pro- } \\
\text { cess annealing rec- } \\
\text { ommended) }\end{array}$ & $\begin{array}{l}\text {-No residual stress is pro- } \\
\text { duced (no post annealing is } \\
\text { needed) }\end{array}$ \\
\hline \multicolumn{2}{|c|}{ Gap tolerance } & $\begin{array}{l}\text {-No limitation when } \\
\text { using filler glass }\end{array}$ & $\begin{array}{l}\text {-Up to } 10 \mu \mathrm{m} \text { was reported, } \\
\text { but further study is needed }\end{array}$ \\
\hline \multicolumn{2}{|c|}{$\begin{array}{l}\text { Typical weld } \\
\text { bead size }\end{array}$} & -mm-size & -Tens to hundred $\mu \mathrm{m}$ size \\
\hline \multicolumn{2}{|c|}{ Future tasks } & $\begin{array}{l}\text {-Technological de- } \\
\text { velopments for } \\
\text { higher throughput } \\
\text { and automation }\end{array}$ & $\begin{array}{l}\text {-Further study on laser- } \\
\text { glass interaction } \\
\text {-Industrially viable weld- } \\
\text { ing technology (e.g. gap } \\
\text { bridging without OC and } \\
\text { sensing technology for au- } \\
\text { tomation) } \\
\text {-Further downsizing of the } \\
\text { weld bead }\end{array}$ \\
\hline
\end{tabular}

also needed, which is a bottleneck in miniaturization of the microsystems such as MEMS and lab-on-a-chip, since the weld bead size depends not only by nonlinear absorption process but by the temperature field due to the heat diffusion in heat accumulation regime. Close contact between glass substrates will become more important especially in downsizing, despite recent efforts for NOC welding as is described in Sec. 4.3. Automation of welding process is also an important task where sensors for in-process monitoring of the weld quality have to be developed, which corelate the weld quality with optical or sound signals. For this purpose, further fundamental study on USP laser-glass interaction is needed, as is demonstrated in laser welding technology of metal $[95,96]$.

The laser welding technology of glass/metal or glass/Si is basically in the similar situation to glass/glass welding by USP lasers in the sense that successful welding requires molten pool having no free-surface $[18,19]$, except that the laser absorption process relies basically on linear process and that the significant problem is melt splash. While both USP and ns lasers can be used for this welding technology, USP laser provides better results for suppressing the melt splash.

Despite of some technological tasks needed, USP laser technology is now almost ready to move from laboratory work to the industrial technology. It is expected that USP laser welding technology will gain much larger market than $\mathrm{CW}$ laser welding in near future.

\section{Acknowledgements}

This work was partially supported by Erlangen Graduate School in Advanced Optical Technologies (SAOT) of the Friedrich-Alexander-University of Erlangen-Nuremberg.

\section{References}

[1] B. G. Yacobi, S. Martin, K. Davis, A. Hudson, and M. Hubert: J. Appl. Phys., 91, (2002) 6227.

[2] P. R. Younger: J. Non-Cryst. Solids, 38-39, (1980) 909.

[3] Q. Wu, N. Lorenz, K.M. Cannon, and D.P. Hand: IEEE Trans. Compon. Packag. Technol., 33, (2010) 470.

[4] V. Greco, F. Marchesini, and G. Molesini: J. Opt. A, Pure Appl. Opt., 3, (2001) 85.

[5] A. W. Y. Tan, and F.E.H. Tay: Sens. Actuators A, 120, (2005) 550.

[6] N. F. Kazakov: "Diffusion bonding of materials," English version: Translated by B.V. Kuznetsov, (Pergamon Press, Oxford, 1985)

[7] I. Miyamoto, and G.A. Knorovsky: "Laser microwelding" in "Microjoining and nanojoining," ed. by Y. Zhou, (Woodhead Publishing, Cambridge, 2008) 345.

[8] L. Pohl, P. von Witzendorff, E. Chatzizyrli, O. Suttmann, and L. Overmeyer: Int. J. Adv. Manuf. Technol., 90, (2017) 397.

[9] E. K. Pfitzer, and R Turner: J. Phys. E: Scientific Instruments, 1, (1968) 360.

[10] Y. Arata, H. Maruo, and I. Miyamoto: Proc. Symp. Electron and Ion Beam Science and Technol. $7^{\text {th }}$ Int. Conf., (1976) 111.

[11]M. Watanabe, and K. Satoh: Tech. Repts of Osaka University, 1(13) (1951). 
[12]T. Terasaki: Proc. $12^{\text {th }}$ Int Offshore and Polar Engineering Conf., Kitakyushu, Japan, (2001) 332.

[13] T. Terasaki: J. Jpn. Welding Soc., 78, (2009) 55.

[14]P. Russbueldt, T. Mans, G. Rotarius, J. Weitenberg, H.D. Hoffmann, and R. Poprawe: Opt. Express, 17, (2009) 12230.

[15]K. Sugioka, and Y. Chen: Appl. Phys. Rev., 1, (2014) 041302.

[16]K. Sugioka: Nanophotonics, 6, (2017) 393.

[17] T. Tamaki, W. Watanabe, J. Nishii, and K. Itoh: Jpn. J. Appl. Phys., 44, (2005) L687.

[18]I. Miyamoto, A. Horn, and J. Gottmann: J. Laser Micro/Nanoeng., 2, (2007) 7.

[19]I. Miyamoto, A. Horn, J. Gottmann, D. Wortmann, and F. Yoshino: J. Laser Micro/Nanoeng., 2, (2007) 57.

[20]I. Miyamoto, K. Cvecek, and M. Schmidt: Opt. Express, 21, (2013) 14291.

[21]I. Miyamoto, K. Cvecek, Y. Okamoto, and M. Schmidt: Appl. Phys. A, 114, (2014) 187.

[22]I. Miyamoto: "Laser welding of glass" in "Handbook of laser welding technologies," ed. by S. Katayama, (Woodhead Publishing, Cambridge, 2013) 301.

[23] S. Richter, F. Zimmermann, S. Döring, A. Tunnermann, and S. Nolte: Appl. Phys. A, 110, (2013) 9.

[24] K. F. Tamrin, Y. Nukman, S. S. Zakariyah: Mat. and Manf. Proc., 28, (2013) 857.

[25]S. Richter, F. Zimmermann, A. Tünnermann, and S. Nolte: Opt. Laser Tech., 83, (2016) 59.

[26]K. Cvecek, S. Dehmel, I. Miyamoto, and M. Schmidt: Int. J. Extrem. Manf., 1, (2019) 042001.

[27]P. K. Kennedy: IEEE J. Quantum Electron., 31, (1995) 2241.

[28]B. C. Stuart, M. D. Feit, S. Herman, A. M. Rubenchik, B. W. Shore, and M. D. Perry: Phys. Rev. B Condens. Matter, 53, (1996) 1749.

[29]A. Vogel, J. Novak, G. Hüttman, and G. Paltauf: Appl. Phys. B, 81, (2005) 1015.

[30] N. Linz, S. Freidank, X. Liang, J. Noack, G. Paltauf, and A. Vogel: AFORS International Research Initiative Project SPC 053010 / EOARD, (2009). http://www.dtic.mil/dtic/tr/fulltext/u2/a521817.pdf.

[31] M. Sun, U. Eppelt, W. Schulz, and J. Zhu: Opt. Mater. Express, 3, (2013) 1716.

[32]I. M. Burakov, N. M. Bulgakova, R. Stoian, A. Mermillod-Blondin, and E. Audouard: J. Appl. Phys., 207, (2007) 043506.

[33]H. S. Carslaw, and J. C. Jaeger, Conduction of Heat in Solids, (Oxford at Clarendon Press, 1959)

[34]A. G. Fedorov, and L. Pilon: J. Non-Crystalline Solids, 311, (2002) 154.

[35] J. Kroos, U. Gratzke, and G. Simon: Appl. Phys. D, 26, (1993) 474.

[36] J. Chen, M. Carter, R. R. Thomson, and D. P. Hand: Opt. Express, 23, (2015) 18645.

[37] M. Levesque, B. Labranche, R. Forest, E. Savard, S. Deshaies, and S. Cournoyer: Phys. Procedia, 5, (2010) 139.

[38]L. Scheafer, and M. Schmidt: Phys. Procedia, 5, (2010) 145.

[39]Datasheet DELO-PHOTOBORND® GB310.

[40] S. Katayama, Y. Abe, M. Mizutani, and Y. Kawahito: Physics Procedia, 12, (2911) 75.
[41] S. Katayama: "Understanding and improving process control in pulsed and continuous wave laser welding," in "Advances in Laser Materials processing - Technology, Research and Applications", eds. by J. Lawrence, J. Pou, D. K. Y. Low. Cambridge: (Woodhead publishing, 2010) 181 .

[42] W. Watanabe, S. Onda, T. Tamaki, K. Itoh, and J. Nishii: Appl. Phys. Lett., 89, (2006) 021106.

[43] Y. Kim, J. Choi, Y. Lee, T. Kim, D. Kim, W. Jang, K. Lim, I. Sohn, and J. Lee: Appl. Phys. A, 101, (2010) 147.

[44]P. Kongsuwan, G. Satoh, and Y.L. Yao: J. Munf. Sci. and Eng., 134, (2012) 011004.

[45] C. B. Schaffer, J. F. Garcia, and E. Mazur: Appl. Phys. A, 76, (2003) 351.

[46]I. Miyamoto, K. Cvecek, and M. Schmidt: Opt. Express, 19, (2011) 10714.

[47] Y. Liu, M. Shimizu, B. Zhu, Y. Dai, B. Qian, J. Qiu,Y. Shimotsuma, K. Miura, and K. Hirao: Opt. Lett., 34 (2009) 136.

[48] K. Kanehira, K. Miura, and K. Hirao: Appl. Phys. Lett., 93, (2008) 023112.

[49] I. Miyamoto, Y. Okamoto, R. Tanabe, Y. Ito, K. Cvecek, and M. Schmidt: Opt. Express, 24, (2016) 25718.

[50]M. Sakakura, M. Shimizu, Y. Shimotsuma, K. Miura, and K. Hirao: Appl. Phys. Lett., 93, (2008) 231112.

[51]I. Miyamoto, K. Cvecek, Y. Okamoto, M. Schmidt, and H. Helvajian: Opt. Express ,19 (2011) 22961.

[52]M. Shimizu, M. Sakakura, M. Ohnishi, M. Yanaji, Y. Shimotsuma, K. Hirao, and K. Miura: Opt. Express, 20 (2012) 934.

[53] S. Wu, D. Wu, J. Xu, Y. Hanada, R. Suganuma, H. Wang, T. Makimura, K. Sugioka, and K. Midorikawa: Opt. Express, 20 (2012) 28893.

[54] S. Wu, D. Wu, J. Xu, H. Wang, T. Makimura, K. Sugioka, and K. Midorikawa1: Opt. Express, 21, (2013) 24049.

[55]S. Richter, F. Zimmermann, R. Eberhardt, A. Tünnermann, S. Nolte: Appl. Phys. A, 121, (2015) 1.

[56] I. Miyamoto, Y. Okamoto, R. Tanabe, and Y. Ito: Phys. Procedia, 56, (2014) 973.

[57]I. Alexeev, J. Heberle, K. Cvecek, K. Yu. Nagulin, and M. Schmidt: Micromach., 6, (2015) 1914.

[58]I. H.W. Nordin, Y. Okamoto, A. Okada, T. Takekuni1, and T. Sakagawa: Appl. Phys. A, 122, (2016) 492.

[59] J. Noack, and A. Vogel: IEEE J. Quantum Electron., 35, (1999) 1156.

[60] A. E. Siegman: “Lasers” (University Science, 1986), Chap. 17.

[61]L. V. Keldysh: Sov. Phys. JETP, 20, (1965) 1307.

[62]F. Docchio: Europhys Lett., 6, (1988) 407.

[63]I. Miyamoto, K. Cvecek, and M. Schmidt: presented at $19^{\text {th }}$ Int. Symp. on Laser Advanced Materials Processing, Edinburgh (2018).

[64]J. Sun, J. Hensel, T. Nitschke-Pagel, and K. Dilger: Materials, 12, (2019) 2700.

[65] http://heraeusquarzglas.de/en/quarzglas/mechanicalpro perties/Mechanical_propertie.

[66] A. Utsumi, T. Ooie, T. Yano, and M. Katsumura: J. Laser Micro/Nanoeng., 2, (2007) 133.

[67] Y. Ozeki, T. Inoue, T. Tamaki, H. Yamaguchi, S. Onda, W. Watanabe, T. Sano, S. Nishiuchi, A. Hirose, and K. Itoh: Appl. Phys. Express, 1, (2008) 82601. 
[68] T. Tamaki, W. Watanabe, and K. Itoh: Opt. Express, 14 (2006) 10460.

[69]K. Cvecek, R. Odato, S. Dehmet, I. Miyamoto, and M. Schmidt: Gap bridging in joining glass using ultra short laser pulses, Opt. Express, 23, (2015) 5681.

[70]Q.-Y. Tong, and U. Gösele: "Semiconductor Wafer Bonding: Science and Technology", (John Wiley \& Sons, 1999).

[71]US Patent US20100084384.

[72]H. Chen, L. Deng, J. Duan, and X. Zeng: Opt. Lett., 44 (2019) 2570.

[73] J. Gottmann, M. Hermans, N. Repiev, and J. Wortmann: Micromachines, 8, (2017) 10.

[74] S. Kim, J. Kim, Y. Joung, J. Choi, and C. Koo: Micromachines, 9, (2018) 639.

[75] K. L. Wlodarczyk, R. M. Carter, A. Jahanbakhsh, A. A. Lopes, M. D. Mackenzie, R. R. J. Maier, D. P. Hand, and M. M. Maroto-Valer: Micromachines, 9, (2018) 409.

[76]S. Bhattacharya, A. Datta, J.M. Berg, and S. Gangopadhyay: J. MEMS, 14, (2005) 590.

[77] S. Kim, J. Park, S. So, S. Ahn, J. Choi, and Y. Joung: Sensors, 81, (2019) 1801.

[78]D. Helie, S. Gouin, and R. Valle: Opt. Mat. Express, 3, (2013) 1743.

[79]A. Couairon, and A. Mysyrowicz: Phys. Rep. 441, (2007) 47.

[80]P. Russell: J. Lightwave Technol., 24, (2006) 4729.

[81]E. Kaiser: Laser Technik J., 3, (2016) 22.

[82] G. Zhang, and G. Cheng: Appl. Opt., 54, (2015) 8957.

[83] K. Yamada, W. Watanabe, T. Toma, K. Itoh, and J. Nishii: Opt. Lett., 26, (2001) 19.

[84]S. Matsuyoshi, Y. Mizuguchi, A. Muratsugu, H. Yamada, T. Tamaki, and W. Watanabe: J. Laser Micro/Nanoeng., 13, (2018) 21.

[85]R. M. Carter, J. Chen, J. D. Shephard, R. R. Thomson, and D. P. Hand: Appl. Opt., 53, (2014) 4233.

[86]R. M. Carter, M. Troughton, J. Chen, I. Elder, R. R. Thomson, M. J. D. Esser, R. A. Lamb, and D. P. Hand: Appl. Opt., 56, (2017) 4873.

[87] O. P. Ciuca, R. M. Carter, P. B. Prangnell, and D. P. Hand: Mater. Charact., 120 (2016) 53.

[88]I. Miyamoto, Y. Okamoto, A. Hansen, J. Vihinen, Tiina Amberla, and J. Kangastupa: Opt. Express, 23, (2015) 3427.

[89]A. Horn, I. Mingareev, A. Werth, M. Kachel, and U. Brenk: Appl. Phys., 93 (2008) 171.

[90]I. H. W. Nordin, Y. Okamoto, A. Okada, H. Jiang, and T. Sakagawa: Appl. Phys. A, 122, (2016) 400.

[91] G. E. Jellison, Jr, and D. H. Lowndes: Appl. Phys. Lett., 41 (1982) 594.

[92]K. Rajkanan, R. Singh, and J. Shewcgun: Solid State Electronics, 22, (1979) 793.

[93] K. Stolberg, B. Kremser, S. Friedel, and Y. Atsuta: J. Laser Micro/Nanoeng., 2, (2007) 7.

[94] G. Wallis, and D. Pomerantz: J. Appl. Phys., 40, (1969) 3946.

[95]I. Miyamoto, and K. Mori: Proc. ICALEO (1995) 759.

[96] A. Ancona, V. Spagnolo, P.M. Lugara, and M. Ferrara:, Appl. Opt., 40, (2001) 6019.

(Received: March 8, 2020, Accepted: August 29, 2020) 